\title{
Constructing the Three-Dimensional Structure of an Anticyclonic Eddy in the South China Sea Using Multiple Underwater Gliders
}

\author{
SHUFENG LI AND SHUXIN WANG \\ School of Mechanical Engineering, Tianjin University, Tianjin, China \\ FUMIN ZHANG \\ School of Electrical and Computer Engineering, Georgia Institute of Technology, Atlanta, Georgia \\ YANHUI WANG \\ School of Mechanical Engineering, Tianjin University, Tianjin, and Joint Laboratory of Ocean Observing \\ and Detection, Pilot National Laboratory for Marine Science and Technology, Qingdao, China
}

(Manuscript received 14 January 2019, in final form 13 August 2019)

\begin{abstract}
Mesoscale eddies have great influence on heat and material transport in the ocean and thus play an important role in modulating the global climate variability. However, our understanding of their fine threedimensional (3D) thermohaline and biogeochemical structure remains incomplete because of the scarcity of high-resolution measurements. This research aims to construct the fine 3D structure of an anticyclonic eddy in the northern South China Sea (NSCS) to validate the effectiveness of a glider network for observing mesoscale eddies. Twelve Petrel gliders were deployed in NSCS during August 2017 to gather fine information of an anticyclonic eddy. By combining the high-resolution in situ glider data and the sea level anomaly data, we have constructed a detailed 3D structure of the eddy. The analysis results of the absolute dynamic topography map and the water mass comparison imply that the anticyclonic eddy may generate from eddy shedding of the Kuroshio loop current. The maximum potential temperature anomaly (over $3^{\circ} \mathrm{C}$ ) appears at the thermocline, and the maximum salinity anomaly ( $\sim 0.8 \mathrm{psu})$ exists at $\sim 50 \mathrm{~m}$. The maximum value of the dissolved oxygen concentration $\left(\sim 7.5 \mathrm{mg} \mathrm{L}^{-1}\right)$ appears at $50-80 \mathrm{~m}$. The maximum chlorophyll concentration $\left(\sim 1.2 \mu \mathrm{g} \mathrm{L}^{-1}\right)$ lies at $80-120 \mathrm{~m}$, just below that of the dissolved oxygen concentration. The colored dissolved organic matter concentration increases with depth, with the mean value being less than $1.23 \mathrm{ppb}$ above $50 \mathrm{~m}$ and beyond $2.2 \mathrm{ppb}$ at $500-800 \mathrm{~m}$. The results verify the capability of the glider network to observe a fine-scaled $3 \mathrm{D}$ structure of mesoscale eddies and will provide a useful guide for future eddy observations.
\end{abstract}

\section{Introduction}

Mesoscale eddies with spatial scales from 50 to $500 \mathrm{~km}$ and temporal scales from 10 to 100 days are ubiquitous in the ocean. They are considerable contributors to the transport of mass, energy (Stammer 1997), and matter or dissolved substances. This makes them one of the key elements for governing the ocean general circulation with important consequences on both climate and marine ecosystems (Mann and Lazier 2013). The 3D structure of an eddy, particularly the structure in the vertical, greatly controls its intensity, endurance, and dissipation $(\mathrm{Hu}$ et al. 2011). The kinetic energy of mesoscale eddies is

\footnotetext{
Corresponding author: Shuxin Wang, shuxinw@tju.edu.cn
}

higher than the average kinetic energy in most regions by an order of magnitude (Richardson 1983). The high variability in spatial and temporal dynamics of mesoscale eddies makes the in situ observation of the 3D structure a great challenge. At present, research about the $3 \mathrm{D}$ structure of eddies is an ongoing effort.

In the previous work, the 3D thermohaline structure of mesoscale eddies has been investigated. Some researchers combined Argo profiles and satellite data to reconstruct the 3D thermohaline structure of mesoscale eddies (Chaigneau et al. 2011; Zhang et al. 2013a; Yang et al. 2013; Amores et al. 2017; Dong et al. 2017; Zhang et al. 2018; He et al. 2018). Limited by the horizontal resolution of Argos, their researches ignored the structure differences among eddies within a domain. To achieve 

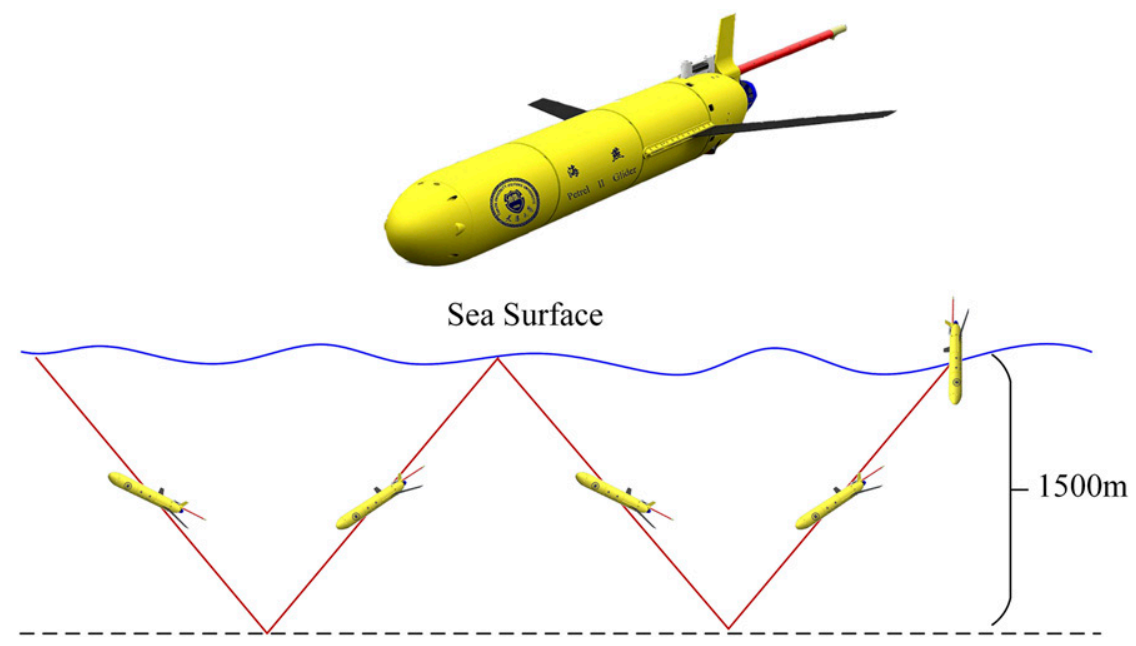

FIG. 1. Petrel II underwater glider developed by Tianjin University, and its sawtooth trajectory in the water column.

dense enough spatial coverage, accumulation of Argo profiles during decades was provided to construct the composite structure of eddies in a surveyed region, assuming that the mesoscale eddies in the domain shared the same structure with the same (Yang et al. 2013; Amores et al. 2017; Dong et al. 2017; He et al. 2018) or opposite (Zhang et al. 2013a; Chaigneau et al. 2011) polarity. Therefore, the reconstructed structure would be the mean pattern of mesoscale eddies occurred in a region during their life spans, which would not reveal the variability of a specific eddy existing in particular periods, such as the generation period, or the termination period. Zhang et al. designed a mooring system with two bottom-anchored mooring arrays deployed in the northern South China Sea (Zhang et al. 2016). The mooring arrays were equipped with ADCPs, recording current meters (RCMs), CTDs, and temperature chains to acquire the full depth current velocity and temperature/salinity data. In their experiment, the vertical intervals of temperature chains in moorings were $10,20,50$, and $100 \mathrm{~m}$, depending on the depth of the sensors mounted on the moorings, and the CTDs were beneath each RCM with the vertical spatial resolution of $400-600 \mathrm{~m}$. The obtained observations with high vertical and temporal resolution were used to investigate the $3 \mathrm{D}$ temperature structure, generation and dissipation processes of mesoscale eddies. However, the horizontal resolution of the mooring system did not provide sufficient data to reconstruct the fine horizontal structure of the eddy. Some oceanographers conducted a vessel-based survey of a mesoscale eddy with $\mathrm{CTD} / \mathrm{XBT} / \mathrm{XCTD}$ probes deployed at predefined stations to reveal the $3 \mathrm{D}$ structural temperature characteristics of the mesoscale eddy ( $\mathrm{Hu}$ et al. 2011; Chu et al. 2014; Chen et al. 2018). In the survey, the fine horizontal structure and dynamic evolution of the eddy were lost due to the limited horizontal resolution and temporal sampling (Nardelli 2013). Besides, only a few literatures have reported the biogeochemical properties within mesoscale eddies. For example, four sets of summertime cruises during the Eddy Dynamic, Mixing,

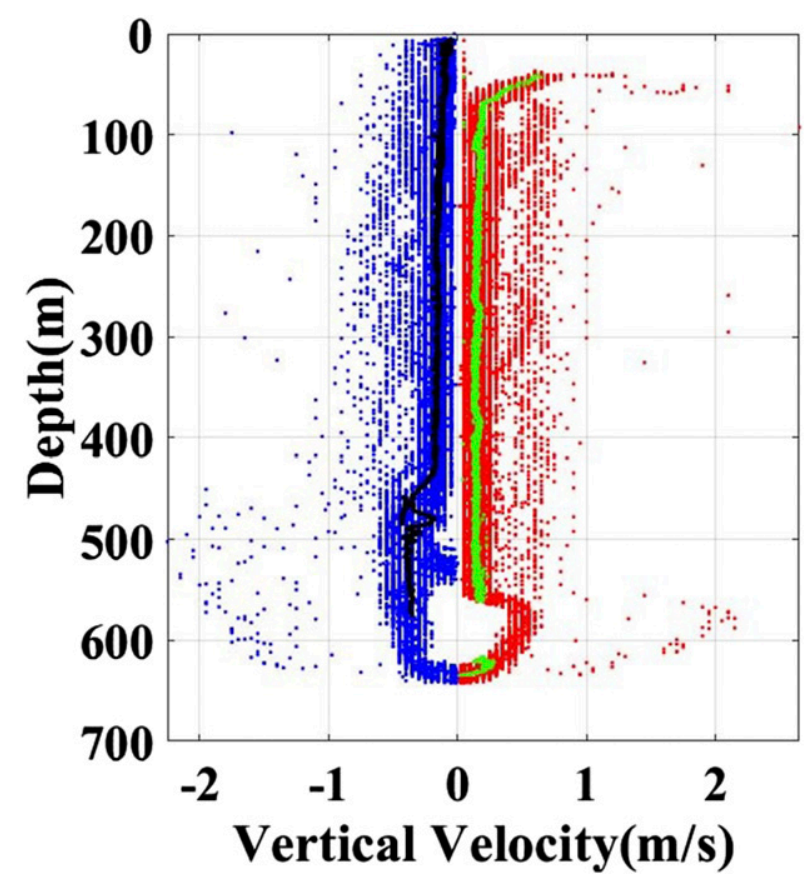

FIG. 2. Vertical velocity of the glider. The red dots and the green line are the vertical velocity and the mean vertical velocity during ascending, respectively. The blue dots and the black line represent the vertical velocity and the mean vertical velocity during descending, respectively. 

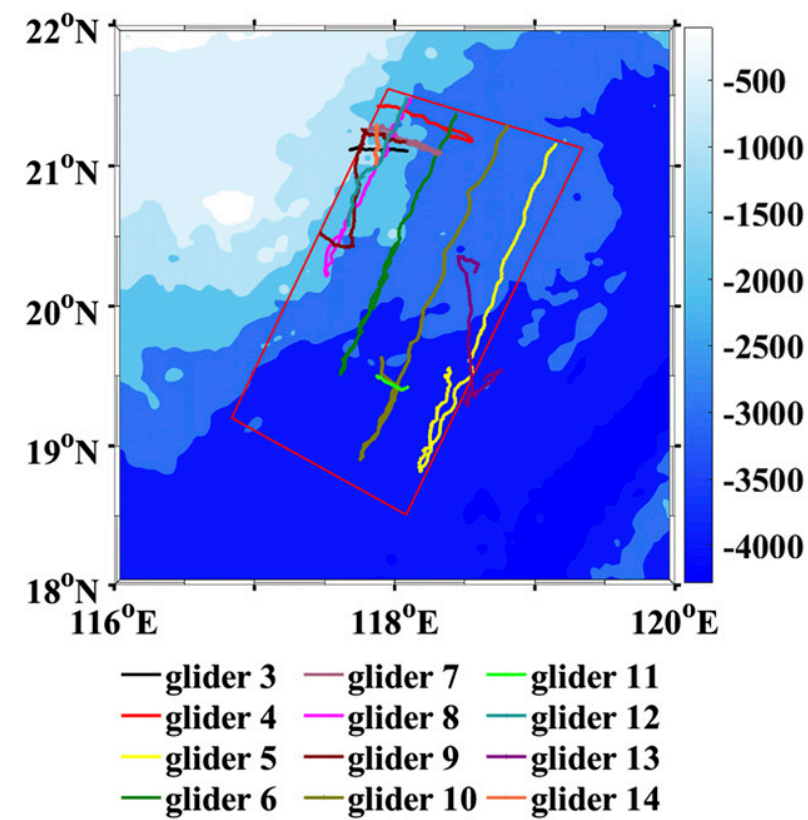

FIG. 3. The trajectories of 12 gliders during 4-29 Aug 2017 in the South China Sea. The surveyed domain has been highlighted by the red rectangle.

Export, and Species Composition (EDDIES) project were conducted to explore the influence of mesoscale eddies on the biogeochemistry of the Sargasso Sea (Li 2007). In the E-Flux III field experiment (an investigation of eddy dynamics in the lee of Hawaii) performed from 10 to 28 March 2005, the measurements from the drifters, satellite and ship were utilized to analyze the physical-biogeochemical interactions within Cyclone Opal (Nencioli et al. 2008). Apart from that, very few fine biogeochemical observations were gathered to characterize the detailed mesoscale eddy structure. The appearance of underwater gliders compensates for the gap of fine in situ observation of mesoscale eddies.
The high spatial resolution and long endurance of underwater gliders help realize submesoscale resolving along their trajectory (Nardelli 2013) and provide continuous long-term observation (Dickey et al. 2008), making their application in the investigation of the mesoscale eddy 3D structure a hotspot. Some researchers deployed a single glider inside the mesoscale eddy, to investigate the eddy structure, the effects of eddy on heat, mass and biogeochemical budgets or the factors that deepen the thermohaline isolines, respectively (Martin et al. 2009; Baird et al. 2011; Cotroneo et al. 2016). Because mesoscale eddies have the features of relatively large spatial and temporal scales and high dynamic variability, acquiring fine information of an eddy with a single underwater glider may cause temporal aliasing (Petillo et al. 2011). Some researchers have focused their attention on resolving the structure of mesoscale eddies with multiple gliders. From 8 to 17 May 2004, five gliders were positioned in a cross array in the Philippine Sea. During the experiment, each glider attempted to hold station at a fixed geographic position to investigate biologicalphysical interactions (Hodges and Fratantoni 2009). To reveal formation mechanism of a subsurface anticyclonic eddy in the Peru-Chile Undercurrent and analyze its effect on near-coastal salinity, oxygen, and nutrient distributions, seven Slocum gliders were launched in the vicinity of the Peru coastline in 2013 (Thomsen et al. 2016). In June and November 2015, the Ocean University of China and the Woods Hole Oceanographic Institution jointly deployed two gliders in the subpolar North Atlantic Ocean. The goal of the operation was to investigate the potentially important role of eddies in modulating northward heat transport in this region (Zhao et al. 2018).

The South China Sea, as the largest and deepest marginal sea surrounded by the Asian continent and the islands of Kalimantan, Palawan, Luzon, and Taiwan in the western North Pacific Ocean, has very complex

TABLE 1 . The deployment time, recovery time, and depth of 12 gliders.

\begin{tabular}{rccc}
\hline \hline No. & Deployment time (UTC) & Recovery time (UTC) & Depth (m) \\
\hline 3 & $1127: 26$ 18 Aug 2017 & $2339: 32$ 19 Aug 2017 & 642 \\
4 & 0622:45 5 Aug 2017 & $1737: 22$ Aug 2017 & 728 \\
5 & $0420: 54$ 4 Aug 2017 & $1806: 35$ 18 Aug 2017 & 804 \\
6 & $1048: 00$ 4 Aug 2017 & $0311: 49$ 17 Aug 2017 & 948 \\
7 & $1006: 00$ 5 Aug 2017 & $0349: 35$ 18 Aug 2017 & 600 \\
8 & $0329: 315$ Aug 2017 & $1651: 13$ 17 Aug 2017 & 897 \\
9 & 0702:36 18 Aug 2017 & $0011: 56$ 25 Aug 2017 & 935 \\
10 & $0734: 35$ 4 Aug 2017 & $0806: 44$ 27 Aug 2017 & 952 \\
11 & $0405: 28$ 19 Aug 2017 & $0056: 57$ 20 Aug 2017 & 738 \\
12 & $03: 32: 47$ 18 Aug 2017 & $1139: 29$ 23 Aug 2017 & 947 \\
14 & $12: 08: 01$ 19 Aug 2017 & $1545: 29$ 29 Aug 2017 & 965 \\
\end{tabular}



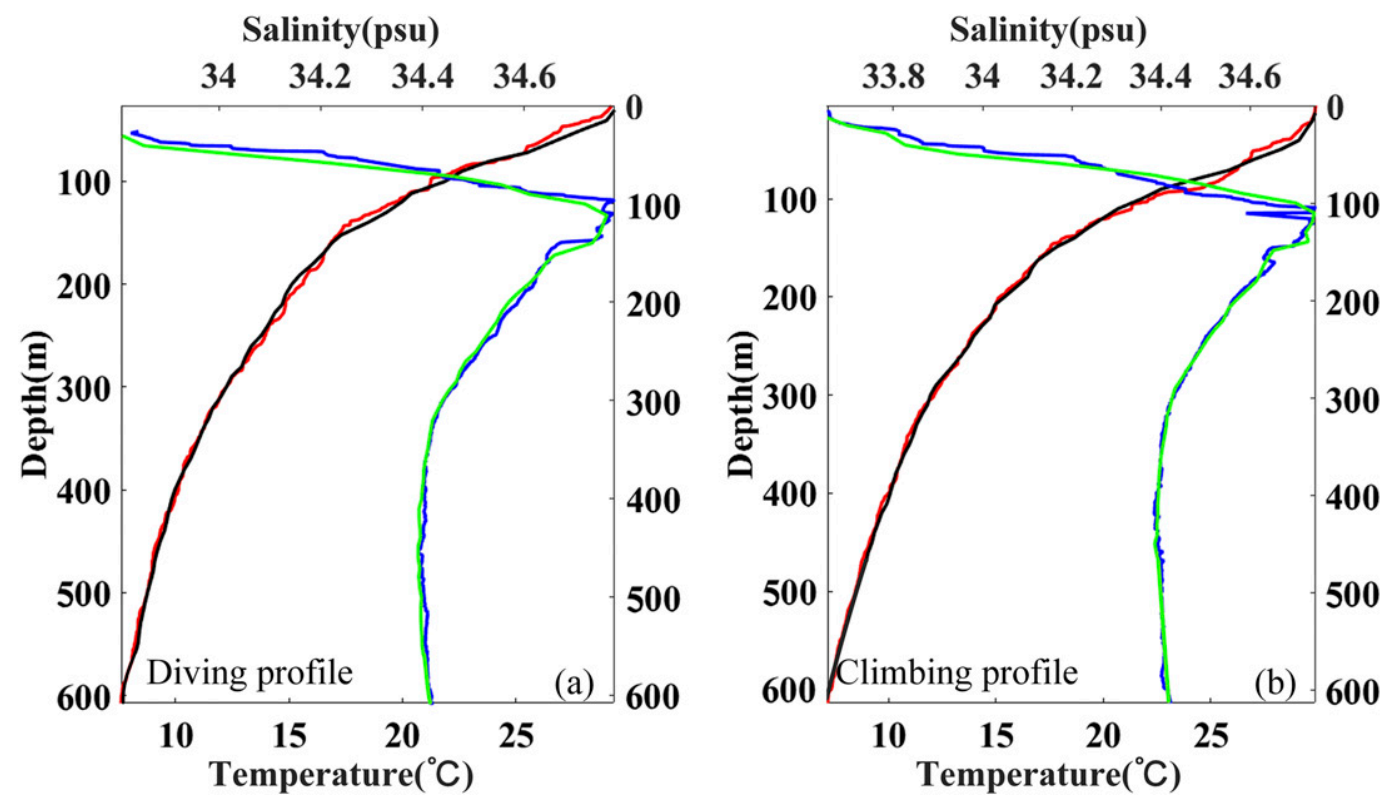

FIG. 4. Raw data vs smoothed data for the (a) diving and (b) climbing profiles. The red and black lines represent the raw and smoothed temperature data, respectively. The blue and green lines show the raw and smoothed salinity data, respectively.

submarine topography (Lin et al. 2015). Asian monsoon system and its interactions with the coastline and submarine topography result in rich mesoscale eddies in the South China Sea (Lin et al. 2015). The mesoscale eddies in the South China Sea have a significant effect on the deep current (Zhang et al. 2013b). However, our understanding of their fine 3D thermohaline and biogeochemical structure remains incomplete because of the scarcity of systematic high-resolution measurements (Zhong et al. 2017). From 4 to 29 August 2017, 12 "Petrel II" underwater gliders developed by Tianjin University were deployed in the northern part of the South China Sea [a trapezoid surrounded by $\left(21.5^{\circ} \mathrm{N}\right.$, $\left.117.9^{\circ} \mathrm{E}\right),\left(21.1^{\circ} \mathrm{N} 119.3^{\circ} \mathrm{E}\right),\left(18.5^{\circ} \mathrm{N} 118.0^{\circ} \mathrm{E}\right)$, and $\left(19.2^{\circ} \mathrm{N}\right.$ $\left.116.8^{\circ} \mathrm{E}\right)$ ], acquiring 1720 fine temperature/salinity profiles and 198 bio-optical profiles totally. As compared with the previous studies that focused on the research of 3D thermohaline structure of mesoscale eddy, the gliders in this study provided not only fine temperature/salinity profiles but also fine biogeochemical measurements, which can reveal the influence of anticyclonic eddies on the biogeochemical processes. In this paper, the high-resolution (about $4.5 \mathrm{~km}$ in the horizontal plane and $0.8 \mathrm{~m}$ in the vertical direction) in situ CTD, biooptical dataset collected by gliders, and satellite data of sea level anomaly (SLA) and absolute dynamic topography (ADT) distributed by the Copernicus Marine Environment Monitoring Service (CMEMS) are integrated. On this basis, we investigated the statistical characteristics of the anticyclonic eddy, explored the vertical structure of potential temperature anomaly, salinity anomaly, potential density anomaly, dissolved oxygen, chlorophyll, and colored dissolved organic matter concentration of the eddy and constructed a composite $3 \mathrm{D}$ structure. Moreover, the origin of the anticyclonic eddy was also studied.

This paper is organized as follows. The second part describes the dataset used in the analysis, including that from Petrel II gliders, CMEMS, and the World Ocean Atlas 2013 (WOA13). The third part investigates the statistic characteristics of the eddy, the origin of the eddy, the vertical fine thermohaline structure of the eddy, and the vertical distribution of dissolved oxygen, chlorophyll and colored dissolved organic matter concentration. The composite 3D structure of the eddy is described in detail. The fourth part summarizes the full paper.

\section{Dataset}

\section{a. Glider dataset}

Underwater gliders are characterized by long operation range (up to several thousand kilometers), long endurance (up to months), and repeatable utilization (Eriksen et al. 2001). They are driven by the buoyancy to move vertically, and use fixed wings to achieve horizontal gliding (Sherman et al. 2001), thus traveling in a sawtooth trajectory. During diving or climbing through the water column, gliders collect a variety of measurements, including temperature, conductivity, dissolved oxygen, current, fluorescence of chlorophyll, sound, etc., 

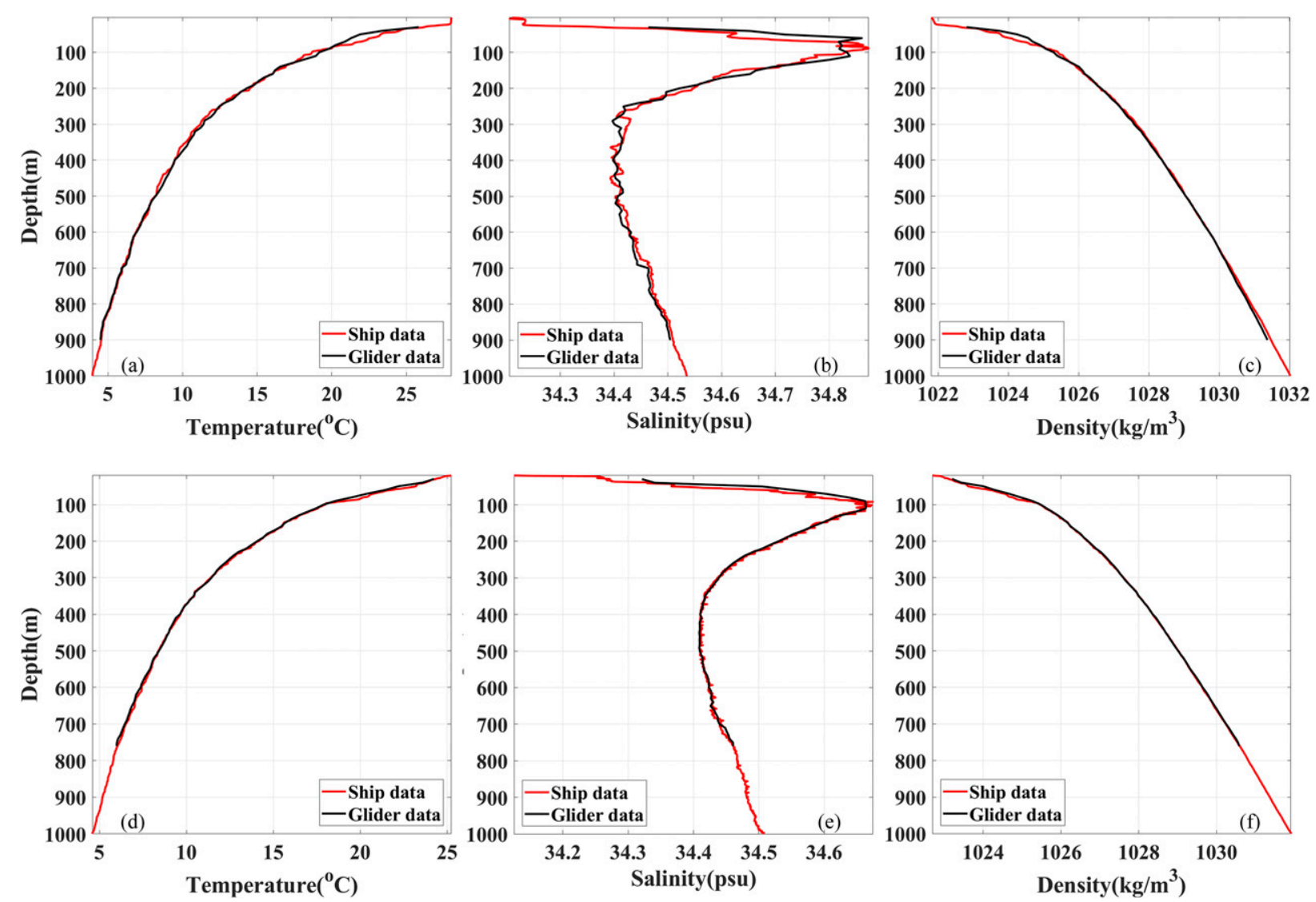

FIG. 5. Comparison between the shipboard CTD data and the CTD data collected by glider 6, showing the shipboard CTD profile vs (a)-(c) the first glider profile and (b)-(d) the last glider profile of the experiment.

depending on the equipped sensors (Shu et al. 2016). The Petrel II underwater gliders (Fig. 1) developed by Tianjin University were applied in the research. Each Petrel II underwater glider can be equipped with multiple physical and biochemical sensors, such as CTD sensor, vector hydrophone, background hydrophone, current meter, MicroRider, and optical backscatter. Each dive cycle of the glider took about $4.5 \mathrm{~h}$ to reach up to $1500-\mathrm{m}$ depth vertically and cover about $4 \mathrm{~km}$ horizontally. However, the horizontal spatial resolution is not constant because the presence of intense currents may impact it (Bouffard et al. 2010). The performance of Petrel II gliders has been validated in repeated sea trials (Liu et al. 2017).

To guarantee the quality of the collected dataset, the vertical velocity of gliders, which is the time derivative of depth observed with the pressure sensor (Martin et al. 2009), should be stable. In Fig. 2, the vertical velocity is mostly in the range of $0-0.3 \mathrm{~m} \mathrm{~s}^{-1}$ during ascending and is from -0.3 to $0 \mathrm{~m} \mathrm{~s}^{-1}$ during descending. The mean vertical velocity is about $0.2 \mathrm{~m} \mathrm{~s}^{-1}$ during the mission within 10-430-m depth when descending and 80-560 m when ascending. At the depth of 560-650 m, the glider completes the adjustment of pitch angle and buoyancy to change from diving to climbing. During this period, the vertical velocity will experience great fluctuation due to the oil flow inside the glider and the start-up of the oil pump.

This experiment was conducted from 4 to 29 August 2017 in the northern South China Sea (Fig. 3) to capture anticyclonic mesoscale eddies using the network constructed by gliders. During the period, an anticyclonic eddy went through the area, which stirred the water column heavily.

In the experiment, 12 Petrel II gliders were deployed within the area of interest (marked as red line in Fig. 3). To better capture the eddy's characteristics, the gliders were deployed and recovered at different positions (Table 1). A SeaBird Glider Payload CTD and a dissolved oxygen (DO) instrument were mounted on the tail of each glider to measure temperature $T$, salinity $S$, pressure, and DO concentration. The sample frequency of the sensor was set to be $0.25 \mathrm{~Hz}$, and, with the mean vertical speed of $0.2 \mathrm{~m} \mathrm{~s}^{-1}$, the vertical resolution of the sampling was about $0.8 \mathrm{~m}$. The observation accuracy of sensor was $\pm 0.002^{\circ} \mathrm{C}$ for temperature, $\pm 0.0003 \mathrm{~S} \mathrm{~m}^{-1}$ 

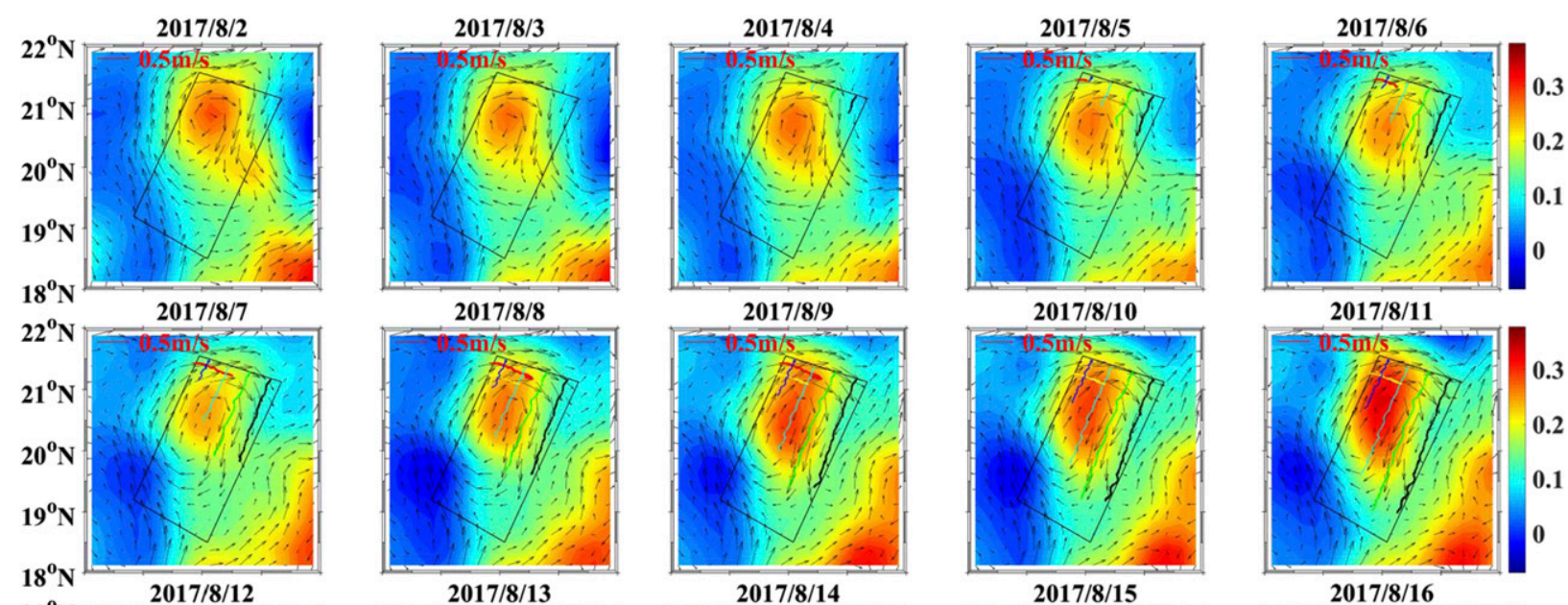

2017/8/10

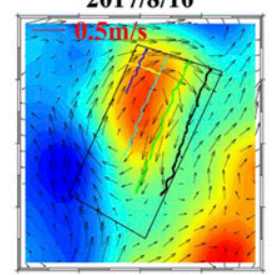

2017/8/11
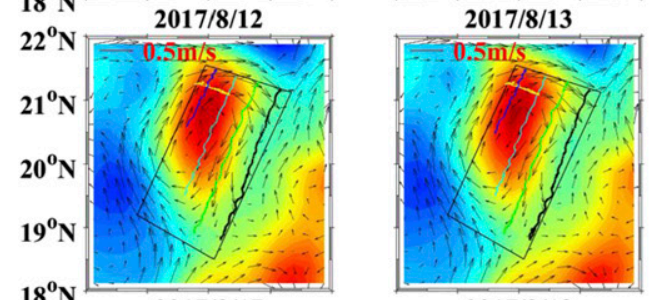

2017/8/14

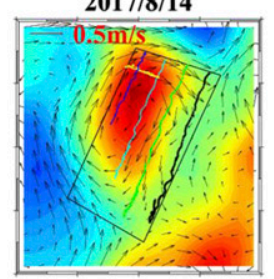

2017/8/15

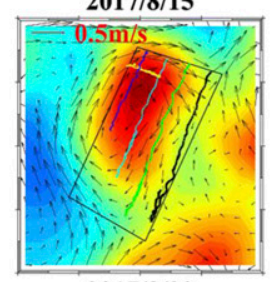

2017/8/20
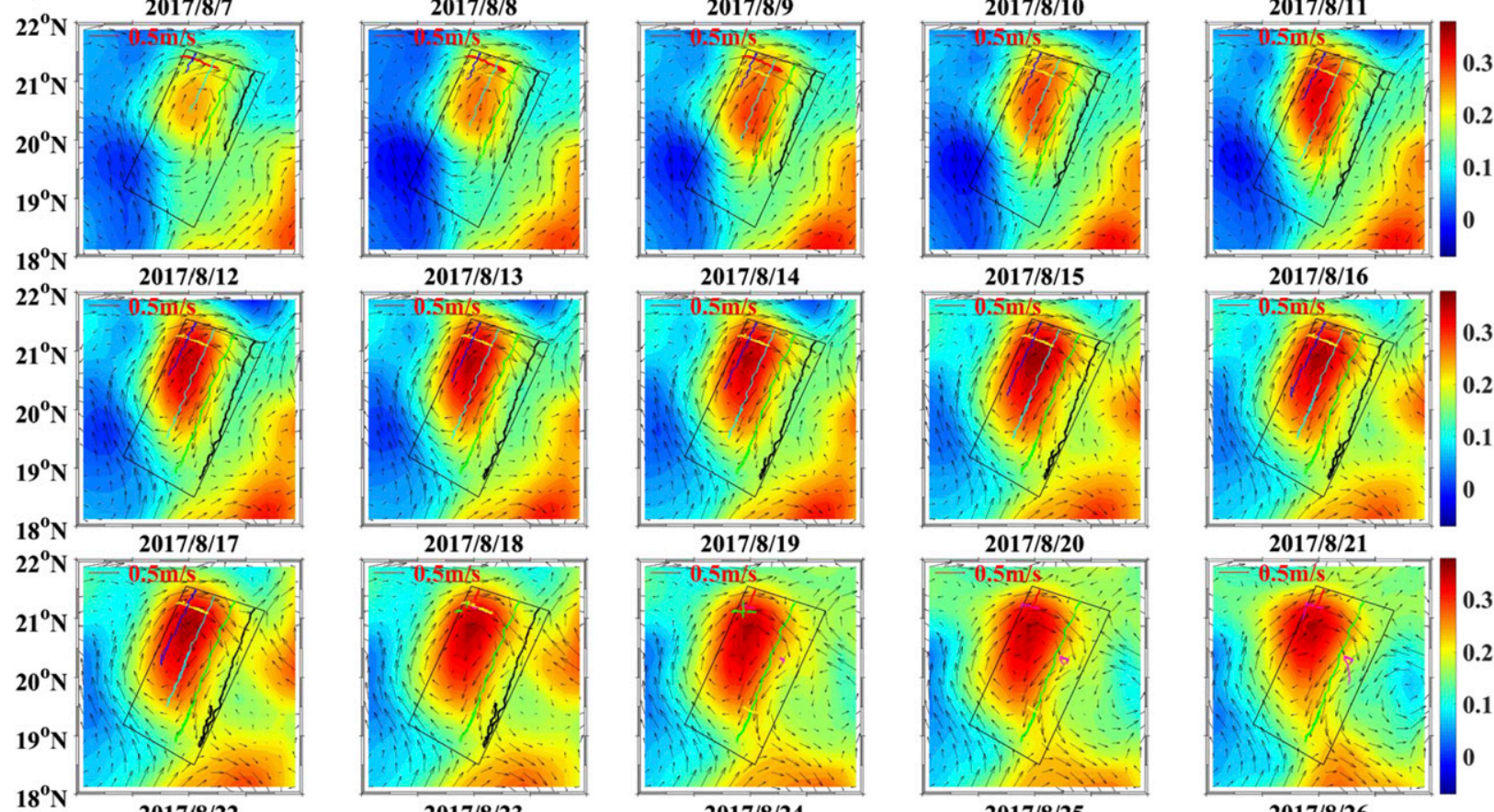

2017/8/23
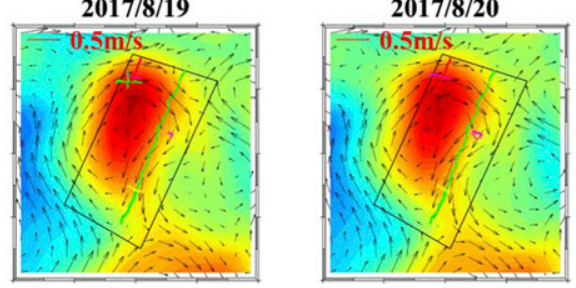

2017/8/24
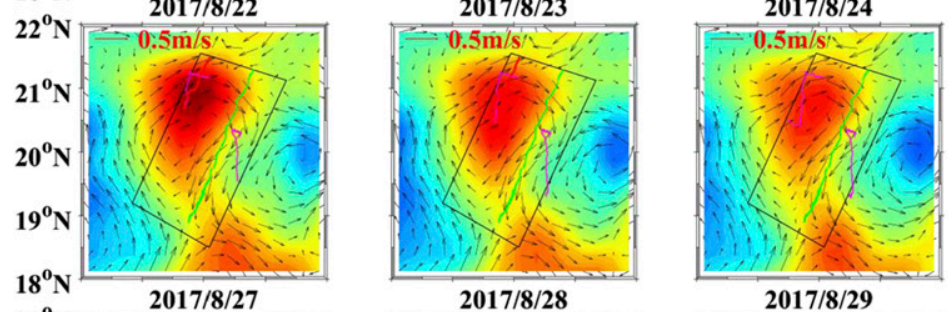

2017/8/25
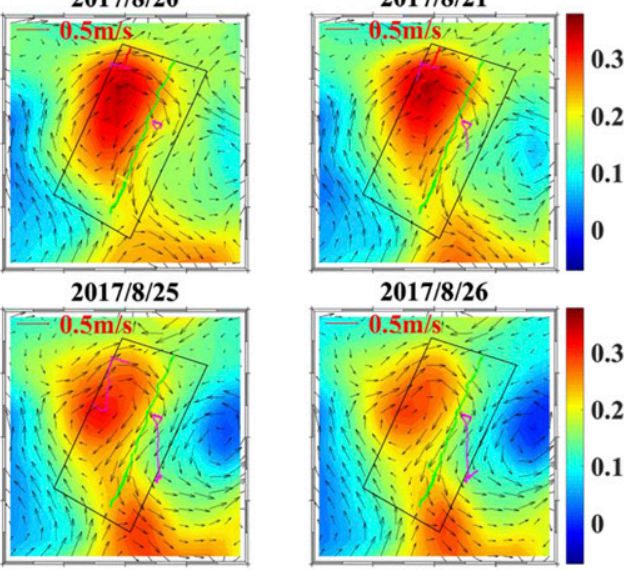

2017/8/28

2017/8/29
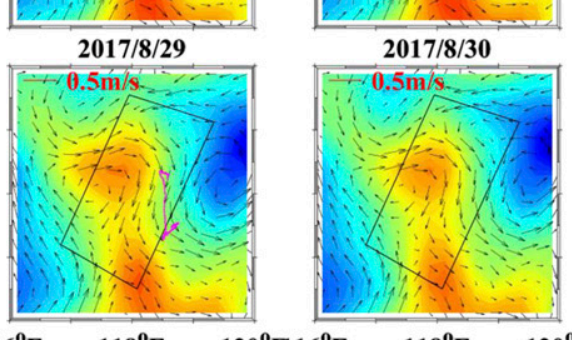

2017/8/31
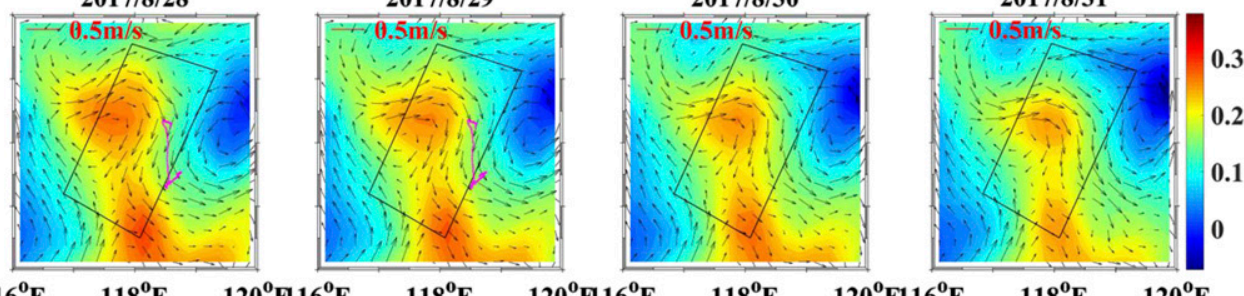

glider $3-$ glider $5 \quad$ glider $7-$ glider $9 \quad$ glider $11-$ glider 13

- glider $4-$ glider $6-$ glider $8 \quad$ glider $10-$ glider $12-$ glider 14

FIG. 6. The time evolution of SLA during the investigation period. The surveyed domain is marked by the black quadrangle. The gliders' paths are also illustrated with colored dotted lines. 


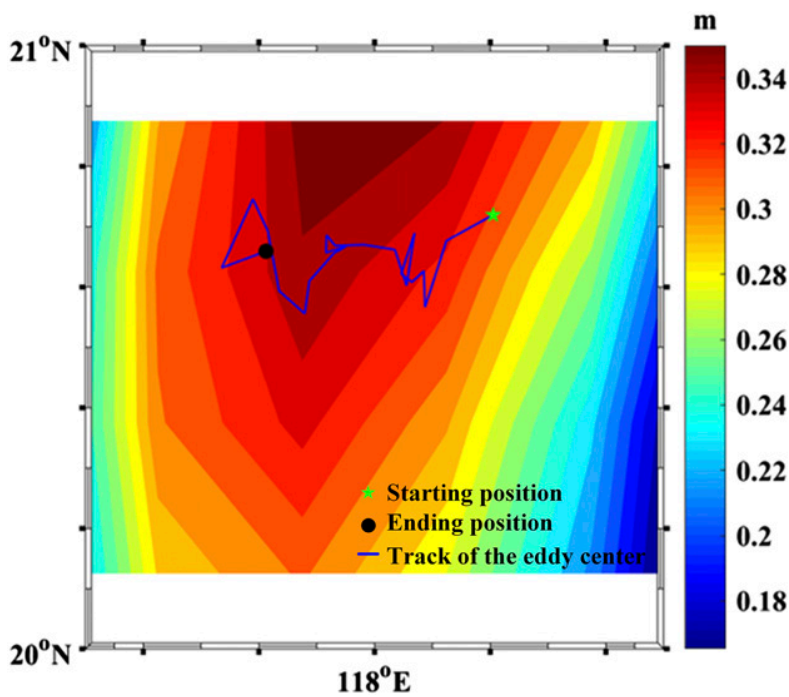

FIG. 7. The track of the eddy during the mission. The color shading represents the SLA map on 14 Aug 2017, and the blue line denotes the track of the eddy center.

for conductivity, and $\pm 0.1 \%$ for pressure. During the experiment, the 12 gliders completed a total of 860 dive cycles. Both upcasts and downcasts were included, so a total of 1720 high-resolution $T / S$ glider profiles were collected with an average horizontal resolution of $2.25 \mathrm{~km}$ and average sampling frequency of $2 \mathrm{~h}$ along glider

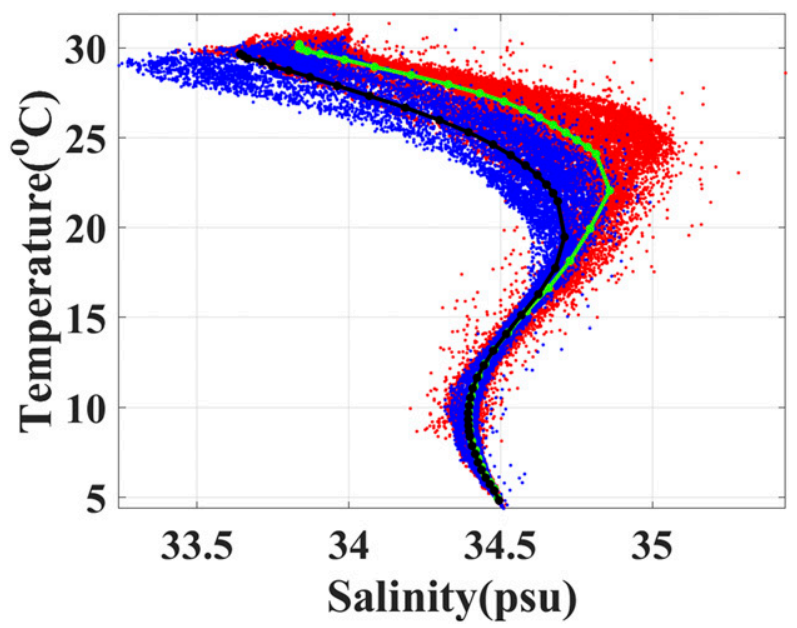

FIG. 8 . The $T-S$ diagram of the profiles collected by gliders. The red and blue dots stand for the profiles inside and outside the eddy, respectively. The green and black dotted lines represent the mean $T-S$ values inside and outside the eddy, respectively. The dots on the curves show the depths, spaced with $5 \mathrm{~m}$ above $100 \mathrm{~m}, 25 \mathrm{~m}$ between 100 and $500 \mathrm{~m}$, and $50 \mathrm{~m}$ between 500 and $1000 \mathrm{~m}$.

horizontal trajectory. In addition, the WETLabs threechannel bio-optical sensor FLBBCDXMU-3947 with chlorophyll fluorometer $(470 / 695 \mathrm{~nm})$, colored dissolved organic matter $(\mathrm{CDOM})$ fluorometer $(370 / 460 \mathrm{~nm})$, and scattering meter $(700 \mathrm{~nm})$ were also integrated on Petrel

TABLE 2. Center position, amplitude, radius, and translation speed of the eddy.

\begin{tabular}{|c|c|c|c|c|}
\hline Date & Center position & Amplitude $(\mathrm{cm})$ & Radius (km) & Translation speed $\left(\mathrm{cm} \mathrm{s}^{-1}\right)$ \\
\hline 4 Aug 2017 & $20.57^{\circ} \mathrm{N}, 118.09^{\circ} \mathrm{E}$ & 11.01 & 109.44 & 15.80 \\
\hline 5 Aug 2017 & $20.63^{\circ} \mathrm{N}, 118.09^{\circ} \mathrm{E}$ & 10.90 & 109.42 & 8.20 \\
\hline 6 Aug 2017 & $20.61^{\circ} \mathrm{N}, 118.06^{\circ} \mathrm{E}$ & 8.65 & 95.97 & 3.67 \\
\hline 7 Aug 2017 & $20.62^{\circ} \mathrm{N}, 118.05^{\circ} \mathrm{E}$ & 7.59 & 89.75 & 3.04 \\
\hline 8 Aug 2017 & $20.69^{\circ} \mathrm{N}, 118.07^{\circ} \mathrm{E}$ & 9.89 & 97.11 & 9.76 \\
\hline 9 Aug 2017 & $20.60^{\circ} \mathrm{N}, 118.06^{\circ} \mathrm{E}$ & 11.96 & 108.34 & 12.07 \\
\hline 10 Aug 2017 & $20.66^{\circ} \mathrm{N}, 118.04^{\circ} \mathrm{E}$ & 12.46 & 108.34 & 8.55 \\
\hline 11 Aug 2017 & $20.67^{\circ} \mathrm{N}, 117.98^{\circ} \mathrm{E}$ & 14.85 & 109.41 & 7.00 \\
\hline 12 Aug 2017 & $20.67^{\circ} \mathrm{N}, 117.93^{\circ} \mathrm{E}$ & 14.96 & 107.29 & 6.42 \\
\hline 13 Aug 2017 & $20.69^{\circ} \mathrm{N}, 117.92^{\circ} \mathrm{E}$ & 14.72 & 107.28 & 3.07 \\
\hline 14 Aug 2017 & $20.66^{\circ} \mathrm{N}, 117.92^{\circ} \mathrm{E}$ & 15.00 & 110.46 & 3.98 \\
\hline 15 Aug 2017 & $20.67^{\circ} \mathrm{N}, 117.95^{\circ} \mathrm{E}$ & 14.42 & 109.42 & 4.65 \\
\hline 16 Aug 2017 & $20.66^{\circ} \mathrm{N}, 117.93^{\circ} \mathrm{E}$ & 13.81 & 108.37 & 3.09 \\
\hline 17 Aug 2017 & $20.63^{\circ} \mathrm{N}, 117.91^{\circ} \mathrm{E}$ & 12.33 & 105.14 & 3.94 \\
\hline 18 Aug 2017 & $20.61^{\circ} \mathrm{N}, 117.89^{\circ} \mathrm{E}$ & 11.85 & 104.05 & 4.41 \\
\hline 19 Aug 2017 & $20.56^{\circ} \mathrm{N}, 117.88^{\circ} \mathrm{E}$ & 11.49 & 105.16 & 7.46 \\
\hline 20 Aug 2017 & $20.59^{\circ} \mathrm{N}, 117.84^{\circ} \mathrm{E}$ & 11.13 & 101.82 & 7.69 \\
\hline 21 Aug 2017 & $20.69^{\circ} \mathrm{N}, 117.82^{\circ} \mathrm{E}$ & 12.03 & 100.64 & 13.81 \\
\hline 22 Aug 2017 & $20.75^{\circ} \mathrm{N}, 117.79^{\circ} \mathrm{E}$ & 12.75 & 102.91 & 7.98 \\
\hline 23 Aug 2017 & $20.63^{\circ} \mathrm{N}, 117.74^{\circ} \mathrm{E}$ & 9.44 & 104.02 & 17.06 \\
\hline 24 Aug 2017 & $20.66^{\circ} \mathrm{N}, 117.81^{\circ} \mathrm{E}$ & 7.37 & 94.72 & 10.54 \\
\hline 25 Aug 2017 & $20.48^{\circ} \mathrm{N}, 117.65^{\circ} \mathrm{E}$ & 7.03 & 84.50 & 32.36 \\
\hline 26 Aug 2017 & $20.53^{\circ} \mathrm{N}, 117.64^{\circ} \mathrm{E}$ & 5.90 & 80.31 & 6.34 \\
\hline 27 Aug 2017 & $20.54^{\circ} \mathrm{N}, 117.62^{\circ} \mathrm{E}$ & 4.96 & 81.73 & 3.49 \\
\hline 28 Aug 2017 & $20.39^{\circ} \mathrm{N}, 117.62^{\circ} \mathrm{E}$ & 3.13 & 66.18 & 20.09 \\
\hline 29 Aug 2017 & $20.35^{\circ} \mathrm{N}, 117.71^{\circ} \mathrm{E}$ & 3.04 & 62.61 & 13.81 \\
\hline
\end{tabular}



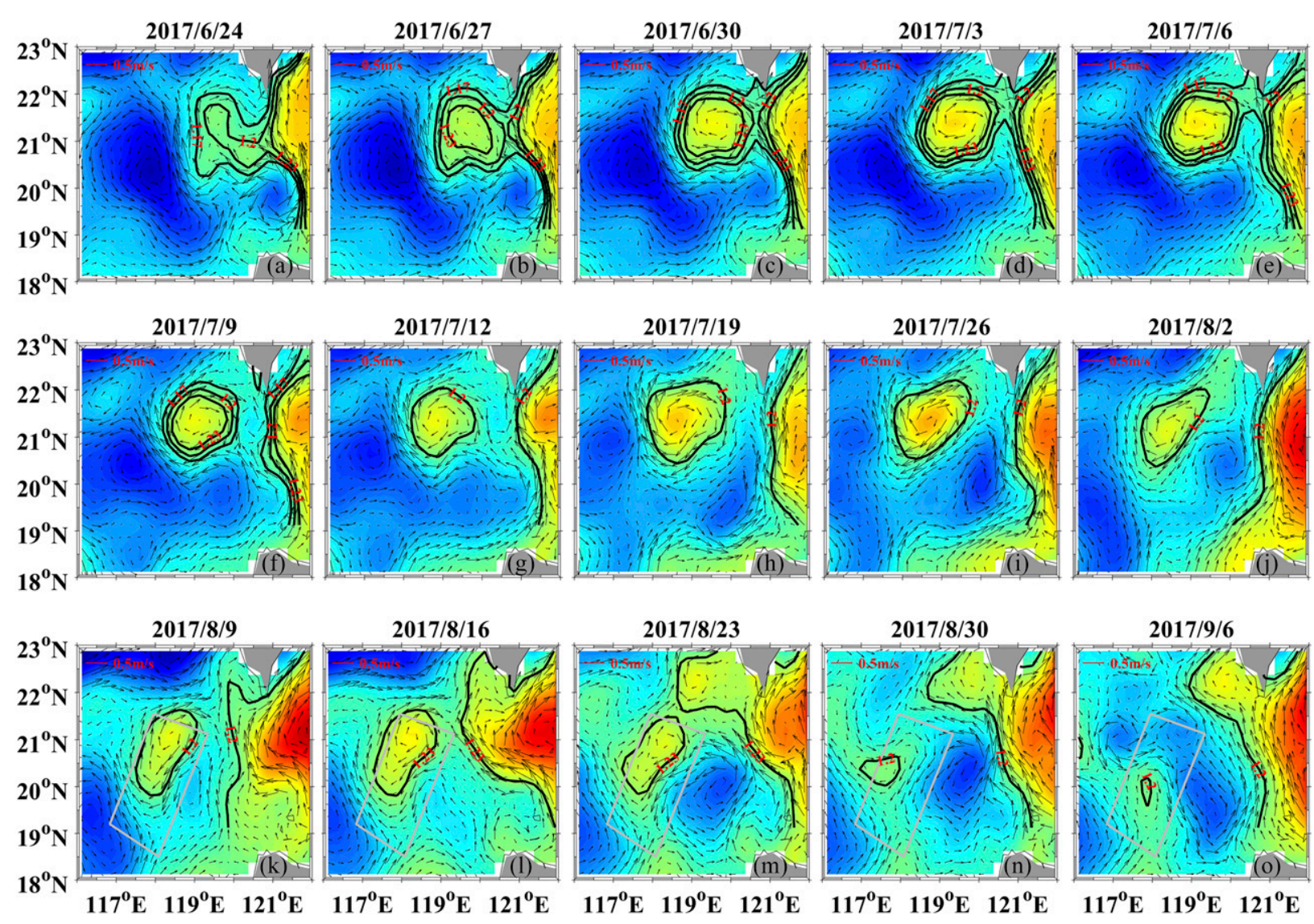

$\begin{array}{lllllll}0.9 & 1 & 1.1 & 1.2 & 1.3 & 1.4 & 1.5\end{array}$

FIG. 9. Eddy shedding and evolution from 24 Jun to 6 Sep 2017. The thick black contours represent the isolines of 1.17, 1.2, and 1.23 m, respectively. The gray quadrangle denotes the surveyed area by gliders during 4-29 August 2017. The reference vector is $0.5 \mathrm{~m} \mathrm{~s}{ }^{-1}$.

II glider 8. With the sampling frequency of $1 \mathrm{~Hz}$, the vertical sampling resolution was $0.2 \mathrm{~m}$. The accuracy of sampling could reach up to $0.025 \mu \mathrm{g} \mathrm{L}^{-1}$ for chlorophyll and $0.184 \mathrm{ppb}$ for CDOM.

The preliminary calibration of CTDs has been done by the manufacturer. Before the experiment, the CTD sensors were calibrated again in National Ocean Technology Center of Tianjin, China. After the mission, the data were downloaded from the internal glider memory and then processed. During the quality control, the spikes occurring in the profiles are removed. To reduce the burrs existing in the measurements of CTDs, the $10-\mathrm{m}$ bin-average smoothing (Liu et al. 2019) is conducted in the $T / S$ profiles processing. In Fig. 4, the smoothed result of the 60th profile of glider 5 is presented as an example. The smoothed data capture the trend of temperature and salinity both in diving and climbing profiles and the burrs have been removed. To verify the data quality, the temperature and salinity profiles collected by each glider are calibrated against the independent CTD casts from the ship cruise before they are used to perform the following analysis. Figure 5 displays the comparison between the shipboard CTD data and the CTD data collected by glider 6 during the first and last dive cycles. It is clearly noted that the temperature and salinity profiles obtained from both first and last glider dive cycles agree well with that from ship cruise. Moreover, the density calculated based on the temperature and salinity measurements also shows a good agreement with that from ship cruise measurements. The raw measurements of DO sensor are processed in the same way as that of CTD. Then DO concentration is calculated according to the manufacturer's calibration coefficients. The chlorophyll fluorometer and CDOM fluorometer have been characterized by the manufacturer using a fluorescent material. Based on the scale factors provided by the manufacturer, the chlorophyll and CDOM concentration can be derived. Then the spikes are removed, a 5-m bin-averaged smoothing is used in the data quality control of the chlorophyll and 


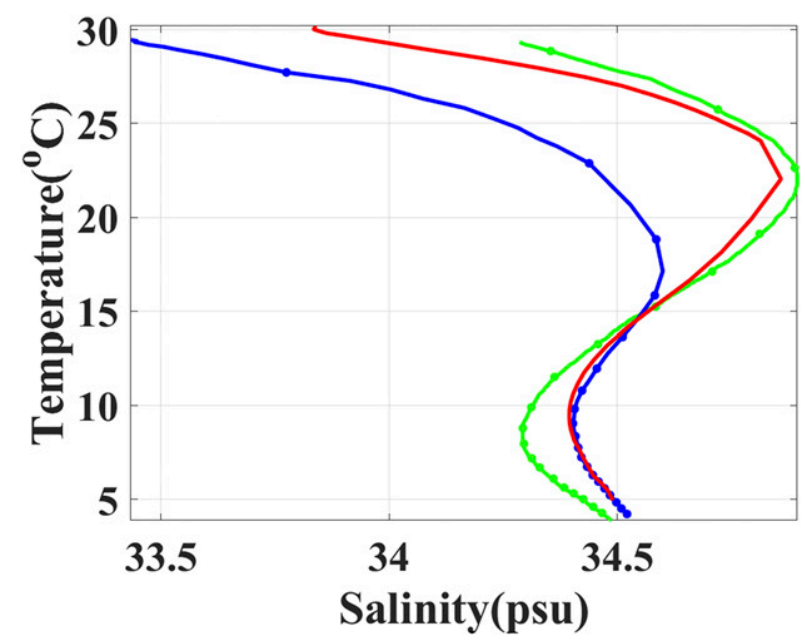

FIG. 10. The $T-S$ diagram of Kuroshio, NSCS, and the eddy water. The blue and green dotted lines represent mean $T-S$ values in NSCS and Kuroshio, respectively, and the dots on the curves show the depths spaced with $50 \mathrm{~m}$. The red line denotes mean $T-S$ of the eddy water.

CDOM concentration and a three-bin vertical running mean is performed to reduce the noise signal (Davies et al. 2019). To remove the high-frequency signals and noises, a 50-km horizontal filtering (Shu et al. 2016) is carried out to smooth the data in horizontal plane.

\section{b. Altimetry dataset}

The global gridded SLA data of the South China Sea from 1 to 31 August 2017 provided by CMEMS [CMEMS has taken over the whole processing and distribution of "segment sol multimissions d'altimétrie, d'orbitographie et de localisation precise" (SSALTO)/Data Unification and Altimeter Combination System (DUACS) gridded and along-track sea level anomalies in delayed time and in near-real time from Archiving, Validation, and Interpretation of Satellite Oceanographic Data (AVISO)] are used to detect the anticyclonic mesoscale eddy and identify its parameters, such as position, radius and amplitude. Besides, the ADT dataset from 15 June to 5 September 2017 confined in a rectangle $\left(18^{\circ}-23^{\circ} \mathrm{N}\right.$, $116^{\circ}-122^{\circ} \mathrm{E}$ ) is also downloaded from CMEMS and used to analyze the origin of the studied eddy. The SLA and ADT dataset is obtained in the merging process of all altimeter missions using an optimal interpolation method to guarantee a better quality of the data (Cotroneo et al. 2016). The spatial resolution of the daily data is $0.25^{\circ}$.

\section{c. Climatological dataset}

The monthly average climatological temperature and salinity are provided by WOA13 to offer the baseline of water characteristics in northern South China Sea water's characteristics (Shu et al. 2016). WOA13 is a long-term set of objectively analyzed climatologies of temperature, salinity, oxygen, phosphate, silicate, and nitrate for annual, seasonal, and monthly periods for the World Ocean. Produced by NOAA's National Oceanographic Data Center, the resolution of the WOA13 is $0.25^{\circ}$ in the horizontal plane and 102 levels in the vertical direction for all variables (Boyer et al. 2013).

\section{d. Method}

The composite analysis method is adopted to obtain the composite structure of the surveyed anticyclonic eddy (Zhang et al. 2016). First, the center-origin coordinate system of the eddy is constructed. The positive directions of the $X$ and $Y$ axes are east and north, respectively. The surveyed domain is divided into $10 \mathrm{~km} \times$ $10 \mathrm{~km}$ mesh grid. Considering the variation of the eddy in radius and intensity, the relative position between profiles and eddy center is normalized by $R / \bar{R}$, where $R$ is the radius of the eddy on the same day with the profile and $\bar{R}$ is the mean of eddy radius. The profiles within
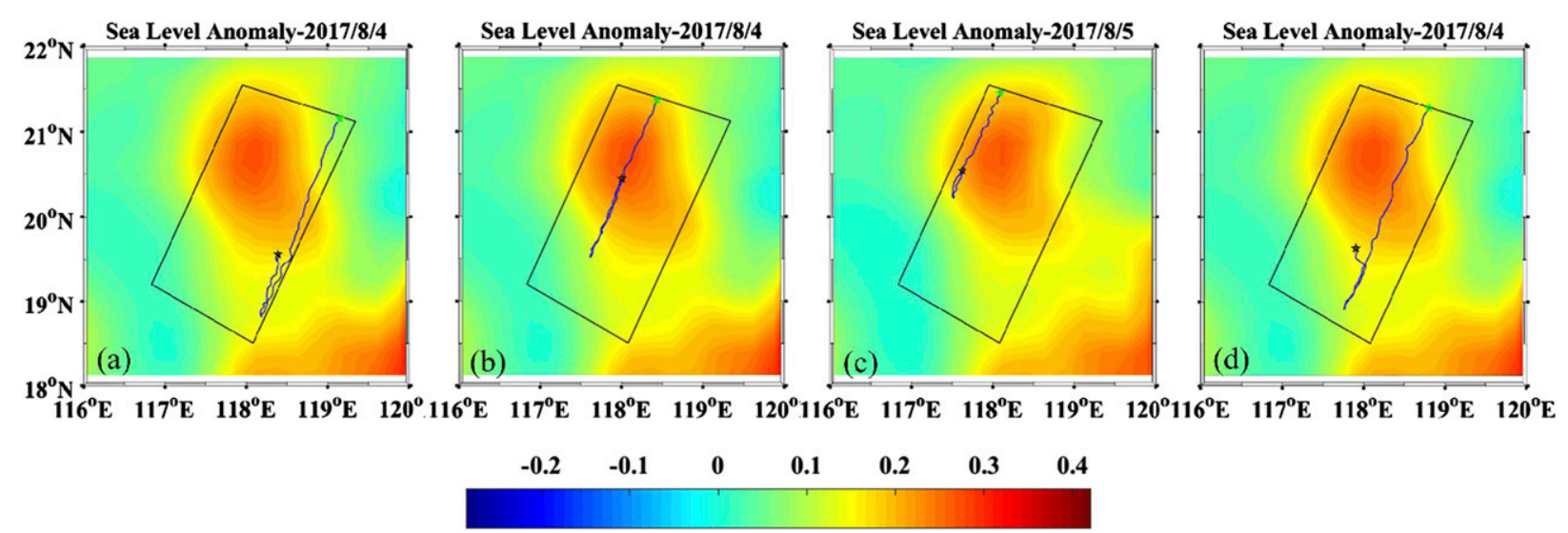

FIG. 11. Trajectory of gliders (a) 5, (b) 6, (c) 8, and (d) 10. 

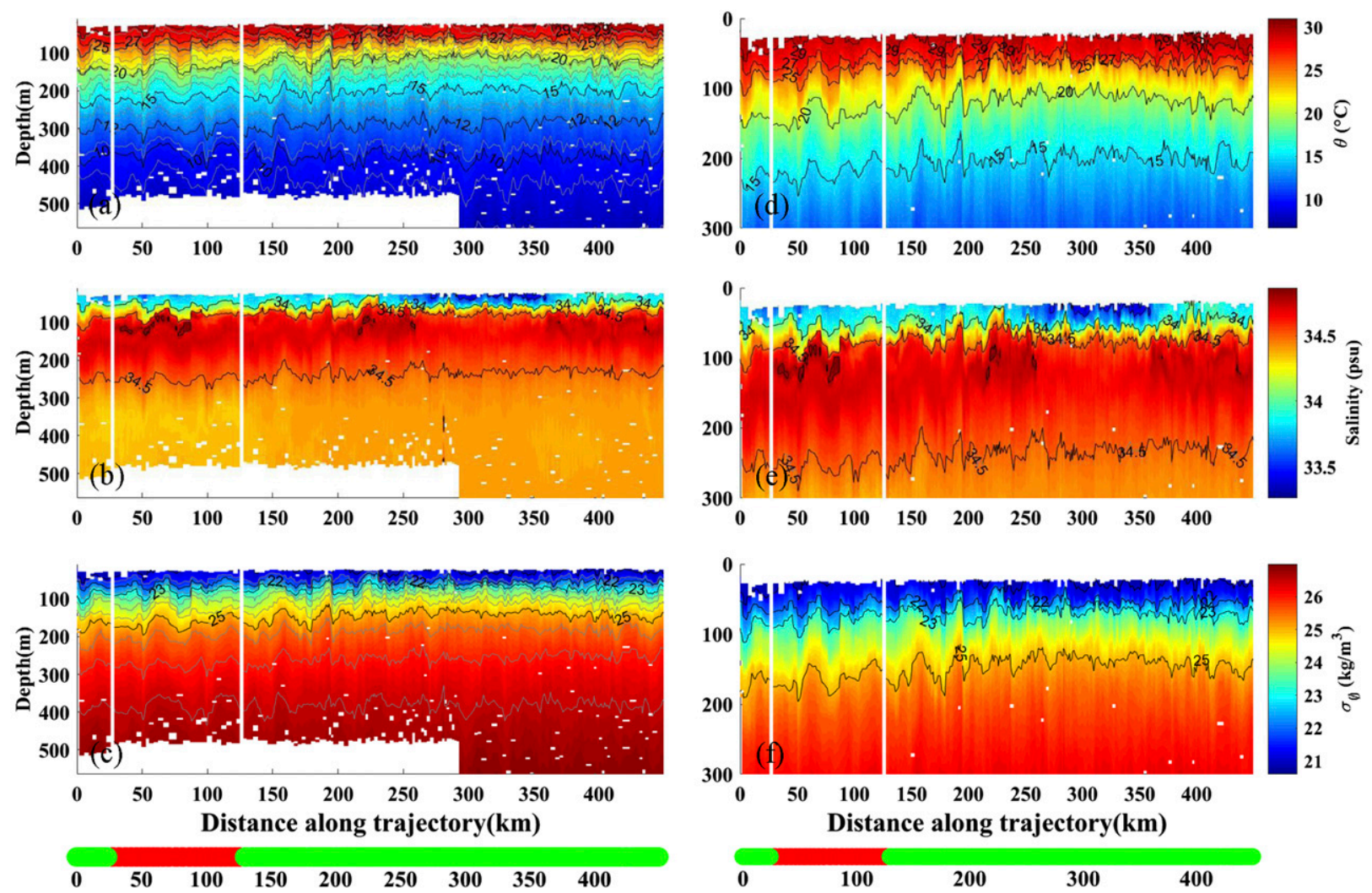

FIG. 12. Vertical sections of (a),(d) $\theta$, (b),(e) $S$, and (c),(f) $\sigma_{0}$ obtained by glider 5 (left) for the entire depth and (right) plotting only above $300 \mathrm{~m}$. The red dots denote the profiles inside the eddy, and the green ones are profiles outside the eddy.

$200 \mathrm{~km}$ from eddy center are selected to conduct the mapping. The temperature and salinity anomalies obtained from gliders (glider dataset minus the climatological monthly mean from the WOA13 dataset) are normalized by $H / \bar{H}$, where $H$ is the eddy amplitude of the same date with the profile and $\bar{H}$ is the mean value of eddy amplitude. Then the mapping is performed. At each grid point, the temperature and salinity anomalies are calculated from the glider profiles with Eq. (1):

$$
\Delta V=\frac{\sum w_{i} \Delta v_{i}}{\sum w_{i}}
$$

where $w_{i}=\exp \left[-\left(d_{i /} L\right)^{2}\right], d_{i}$ is the distance between the $i$ th profile and the interpolated grid point, $L(50 \mathrm{~km})$ is the influence radius, $\Delta v_{i}$ represents the glider anomaly profiles, and $\Delta V$ is the anomaly at the interpolated grid point.

\section{Results}

\section{a. Satellite observation of the eddy}

To perform 3D structure reconstruction of the eddy, the information of the anticyclonic eddy at the surface should be known before the analysis. The SLA dataset confined in a rectangle $\left(15^{\circ}-25^{\circ} \mathrm{N}, 110^{\circ}-122^{\circ} \mathrm{E}\right)$ during 1-31 August 2017 from CMEMS is employed to identify the anticyclonic eddy. The time evolution of SLA is shown in Fig. 6. It can be clearly noted that a positive SLA center appears in the surveyed domain (the black quadrangle), suggesting an anticyclonic eddy. From 2 to 31 August, the shape, size, and strength of the eddy-like SLA vary greatly and the 12 glider cruises start in different sites and dates. Gliders 3, 4, 7, and 11 sail from the northwest to southeast of the eddy while gliders $5,6,8$, $10,12,13$, and 14 travel from the northeast to the southwest of the eddy, among which gliders 5 and 13 perform missions outside the eddy. The cruise of glider 9 is divided into three parts. The first and third parts collect data along the northwest-southeast direction and the second part samples the eddy from northeast to southwest.

The eddy parameters such as radius, amplitude, and translation speed can be determined from the SLA map using the method of Faghmous et al. (2015). The track of the anticyclonic eddy during the operation of the experiment is shown in Fig. 7 by comparing the consecutive SLA maps. In Fig. 7, the SLA map in the domain on 14 August 2017 is displayed and the blue line represents the track of 

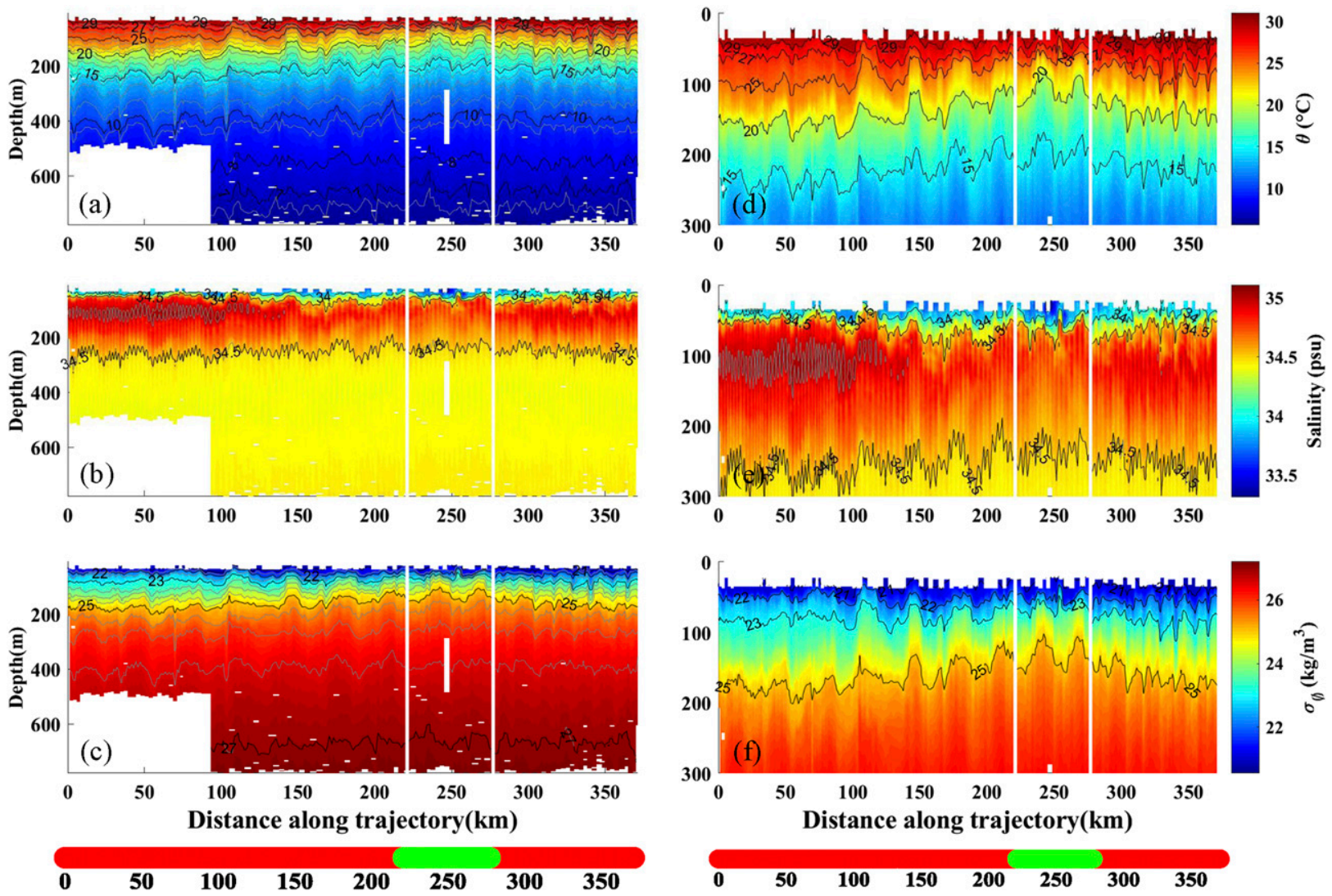

FIG. 13. As in Fig. 12, but for glider 6.

the eddy center. The green star and black dot represent the starting and ending positions of the eddy center during the glider mission. As shown in Fig. 7, there exists a tendency of moving from east toward west for the eddy.

Eddy parameters like radius, amplitude and position of the eddy center during the mission are shown in Table 2. Radius ranges from 62.61 to $110.46 \mathrm{~km}$ with a maximum value of $110.46 \mathrm{~km}$ on 14 August and the average value of $98 \mathrm{~km}$. Eddy amplitude, the maximum SLA value in anticyclonic eddy, is estimated to be in the range of 3.03$15 \mathrm{~cm}$. The maximum value is $15 \mathrm{~cm}$ above the mean sea surface during the mission, and the mean value is calculated as $10.49 \mathrm{~cm}$. The translation speed is computed on the basis of the eddy center position in consecutive SLA maps (Cotroneo et al. 2016). The fifth column of Table 2 reveals the daily translation speed of the eddy during the glider operation. Mean value of the translation speed is $9.16 \mathrm{~cm} \mathrm{~s}^{-1}$ while the maximum could reach up to more than $30 \mathrm{~cm} \mathrm{~s}^{-1}$ during the mission. The mean speed agrees well with the previous literature.

\section{b. Water mass}

To characterize the difference of water mass inside and outside the anticyclonic eddy, the $T-S$ diagram of data collected by gliders is illustrated in Fig. 8. All glider $T / S$ profiles during the mission from 4 to 29 August 2017 are divided into two parts: inside and outside the eddy. In Fig. 8, the red and blue dots stand for the profiles inside and outside the eddy, respectively. The green and black dotted lines represent the mean $T-S$ values inside and outside the eddy, respectively. As shown in Fig. 8, there exists an obvious difference in the property of water mass inside and outside the eddy. The water trapped within the eddy area exhibits a higher salinity than that outside the eddy with the difference of about 0.3 "practical salinity units" (psu).

The eddy may stem locally from the northern South China Sea (NSCS) or from the Kuroshio water (Shu et al. 2019; Zhang et al. 2017). To investigate the origin of the eddy, the eddy shedding of Kuroshio from 24 June to 6 September 2017 is studied. The ADT data and surface geographic velocity from CMEMS are plotted to illustrate the eddy shedding and evolution process. As shown in Fig. 9, a Kuroshio loop current is seen in Luzon Strait on 24 June 2017 and bends westward. On 27 June, an anticyclonic eddy forms in the loop current. It detaches from the Kuroshio loop current on 9 July and moves westward first and then southwestward. During the 

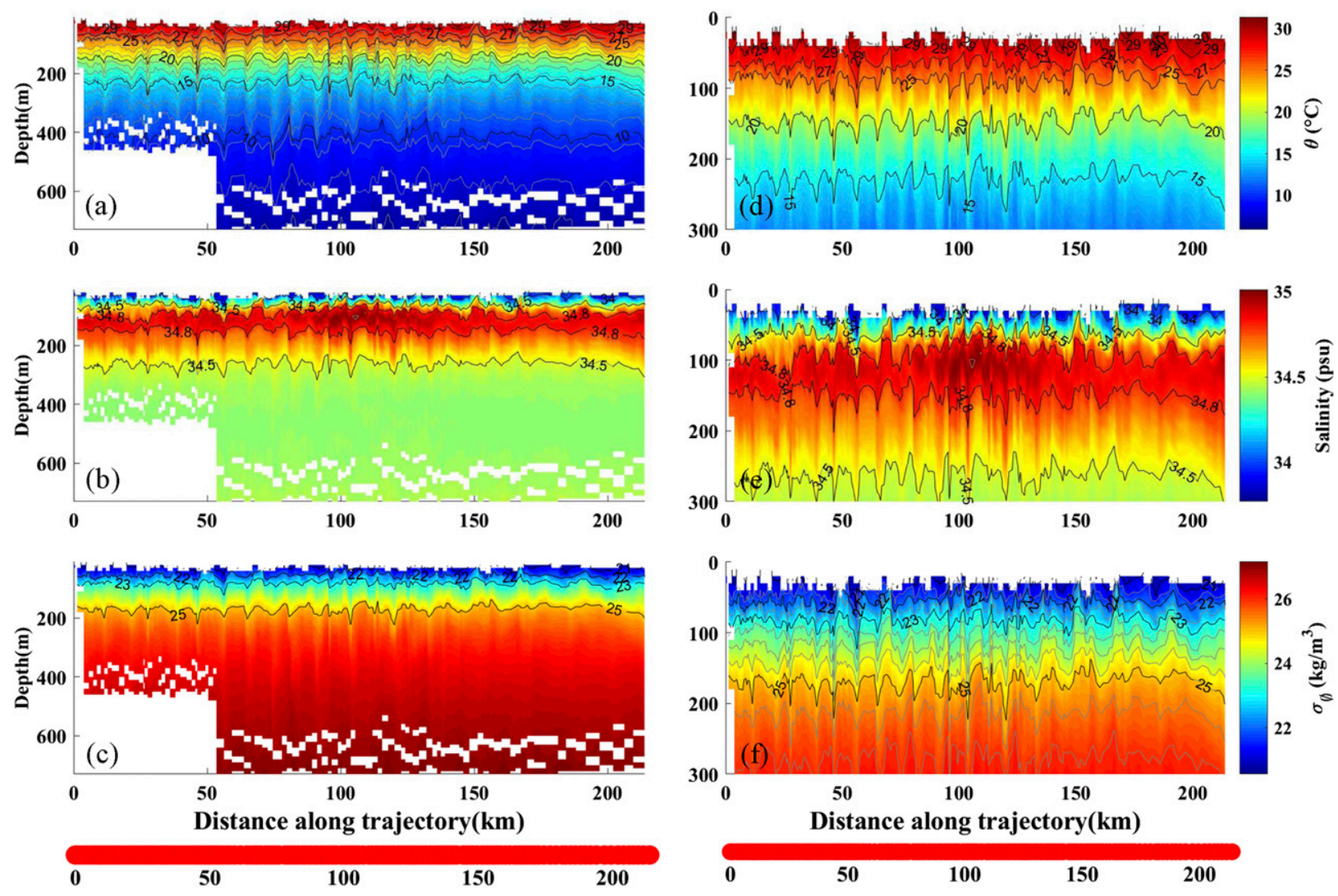

FIG. 14. As in Fig. 12, but for glider 8.

missions from 4 to 29 August 2017, the eddy arrives within the study area, shown as the gray quadrangle in Fig. 9. Therefore, it is proved that the studied anticyclonic eddy separates from the Kuroshio loop current, agreeing with the results of the literature (Shu et al. 2019).

The water mass characteristics of NSCS, Kuroshio water and eddy area are investigated by comparing the mean $T-S$ values of NSCS, Kuroshio and eddy water. Since the glider mission did not cover the two regions, the temperature and salinity data within the two regions are obtained from historical Argo $T / S$ profiles. As shown in Fig. 10, the mean $T-S$ values in NSCS and Kuroshio are, respectively, presented in blue and green dotted lines. The $T-S$ property of the eddy water is shown by a red line. As shown in Fig. 10, in the upper layer, the Kuroshio water obviously displays higher temperature and salinity than those in NSCS. However, the property is reversed in the intermediate layer where the Kuroshio water is colder and fresher than NSCS water. The eddy water shows more similarity in the $T-S$ characteristics with the Kuroshio water above $300 \mathrm{~m}$, while the difference in salinity between the eddy water and NSCS water at the surface reaches about $0.43 \mathrm{psu}$. The similarity between the eddy water and Kuroshio suggests that the anticyclonic eddy may come from Kuroshio. However, the eddy water is slightly colder and fresher than Kuroshio water, which may result from entrainment of some SCS water or water mass transformation due to diurnal mixing induced by strong tides (Zhang et al. 2017). Besides, the mean $T-S$ diagram exhibits similar properties between the eddy water and NSCS water in the intermediate layer, implying that the eddy originated from the Kuroshio traps the Kuroshio water in the upper $300 \mathrm{~m}$, agreeing with the results of the previous literature (Zhang et al. 2017). However, the previous study suggested that the Kuroshio loop current eddy shedding mainly occurred in boreal autumn and winter. Actually, the phenomenon appears to be rare in summer and other seasons than in winter (Yuan et al. 2006). The reason why this anticyclonic eddy shedding occurred in summer is not so clear but may relate to the positive geostrophic vorticity between the high sea surface height center located inside the anticyclonic eddy west of the Luzon Strait and that inside the Kuroshio bend east of the Luzon Strait (Jia and Liu 2004).

\section{c. Temperature, salinity, and density sections}

To better display the vertical structure of the eddy, the data collected by gliders $5,6,8$, and 10 , which crossed the 

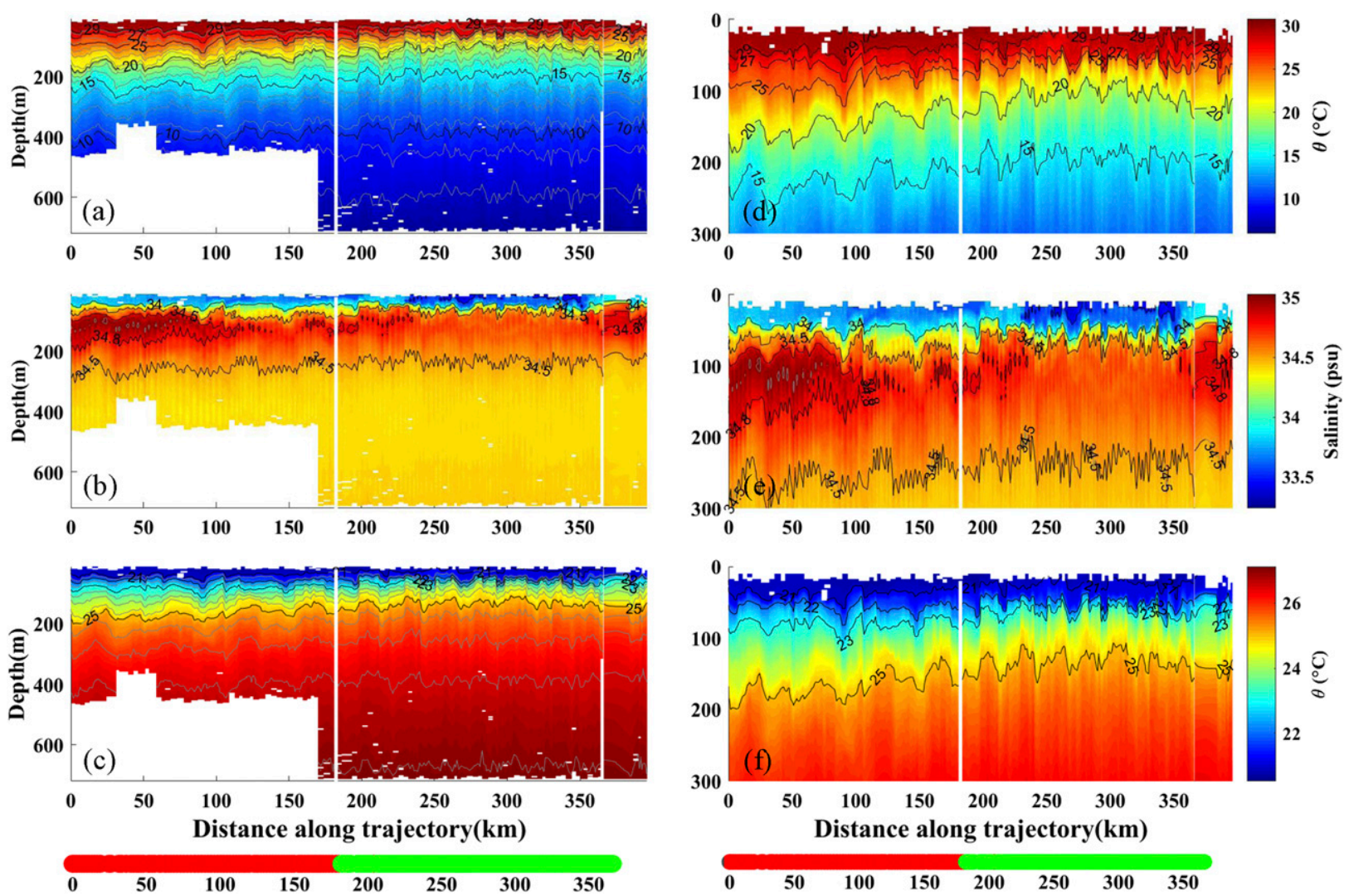

FIG. 15. As in Fig. 12, but for glider 10.

eddy during their missions, are plotted. Trajectories of the four gliders are shown in Fig. 11, where the color map represents the SLA downloaded from CMEMS on each glider deployment date. The green and black stars are the deployment locations and the recovery locations, respectively. Gliders 5, 6, 8, and 10 all survey from northeast to southwest; each glider takes transects of the eddy along their individual trajectory.

Vertical sections of potential temperature $\theta$, salinity $S$, and potential density $\sigma_{0}$ obtained by the four gliders in the eddy during their missions are shown in Figs. 12-15, respectively. The $X$ axis in these figures is the glider's trajectory. In Fig. 11, glider 5 samples the southeast part of the anticyclonic eddy during 4-18 August 2017. Figures $12 \mathrm{~d}$ and $12 \mathrm{f}$ show a sinking of isotherms and isopycnals in $\theta$ and $\sigma_{0}$, which suggest the presence of an anticyclonic eddy. In Figs. 12d and 12f, the isotherm of $20^{\circ} \mathrm{C}$ and isopycnal of $25 \mathrm{~kg} \mathrm{~m}^{-3}$ both sink for about $30 \mathrm{~m}$. Vertical sections of potential temperature anomaly $\theta^{\prime}$, salinity anomaly $S^{\prime}$, and potential density anomaly $\sigma_{0}^{\prime}$ obtained by the four gliders are shown in Figs. 16 and 17 . The anomalies are calculated by subtracting the climatological values from glider dataset. In Figs. 16a and $16 \mathrm{~b}$, there exists a water mass with the maximum $\theta^{\prime}$ of more than $2^{\circ} \mathrm{C}$ at about $120 \mathrm{~m}$ and $S^{\prime}$ of about $0.5 \mathrm{psu}$ at $50 \mathrm{~m}$ in the anticyclonic eddy. The maximum value of $\sigma_{0}^{\prime}$ is about $-0.5 \mathrm{~kg} \mathrm{~m}^{-3}$ in Fig. 16c. As shown in Fig. 11b, glider 6 crosses the eddy. The vertical thermohaline structure obtained by glider 6 is shown in Figs. 13d-f, indicating a higher salinity with a maximum value of about $35 \mathrm{psu}$, and a sinking of the isotherm of $20^{\circ} \mathrm{C}$ from about 120 to $150 \mathrm{~m}$ in the eddy, while the isopycnal of $25 \mathrm{~kg} \mathrm{~m}^{-3}$ sinks from about 150 to $180 \mathrm{~m}$. According to the depth reached by the isolines of $\theta$ and $\sigma_{0}$, the vertical extension of the eddy in this section could be more than $700 \mathrm{~m}$. Correspondingly, in Figs. 16d-f, the anomalies also display the presence of the eddy, and the maximum anomalies of $\theta, S$ and $\sigma_{0}$ are about $3^{\circ} \mathrm{C}$ at about $120 \mathrm{~m}$, the depth of the thermocline, more than 0.5 psu at about $50 \mathrm{~m}$, the depth of the mixed layer, and $-0.6 \mathrm{~kg} \mathrm{~m}^{-3}$ at about $150 \mathrm{~m}$, respectively. Most values of $\theta^{\prime}$ are between 50 and $200 \mathrm{~m}$ (indicated by the dashed white line in Fig. 16d). The maximum depth of $S^{\prime}$ is about $200 \mathrm{~m}$ (indicated by the dashed white line in Fig. 16e). The negative $\sigma_{0}^{\prime}$ exists below $100 \mathrm{~m}$ (indicated by the dashed white line in Fig. 16f) with the maximum value of more than $0.6 \mathrm{~kg} \mathrm{~m}^{-3}$ while the positive $\sigma_{0}^{\prime}$ exists in the mixed layer with the maximum of $0.5 \mathrm{~kg} \mathrm{~m}^{-3}$. Glider 8 takes 

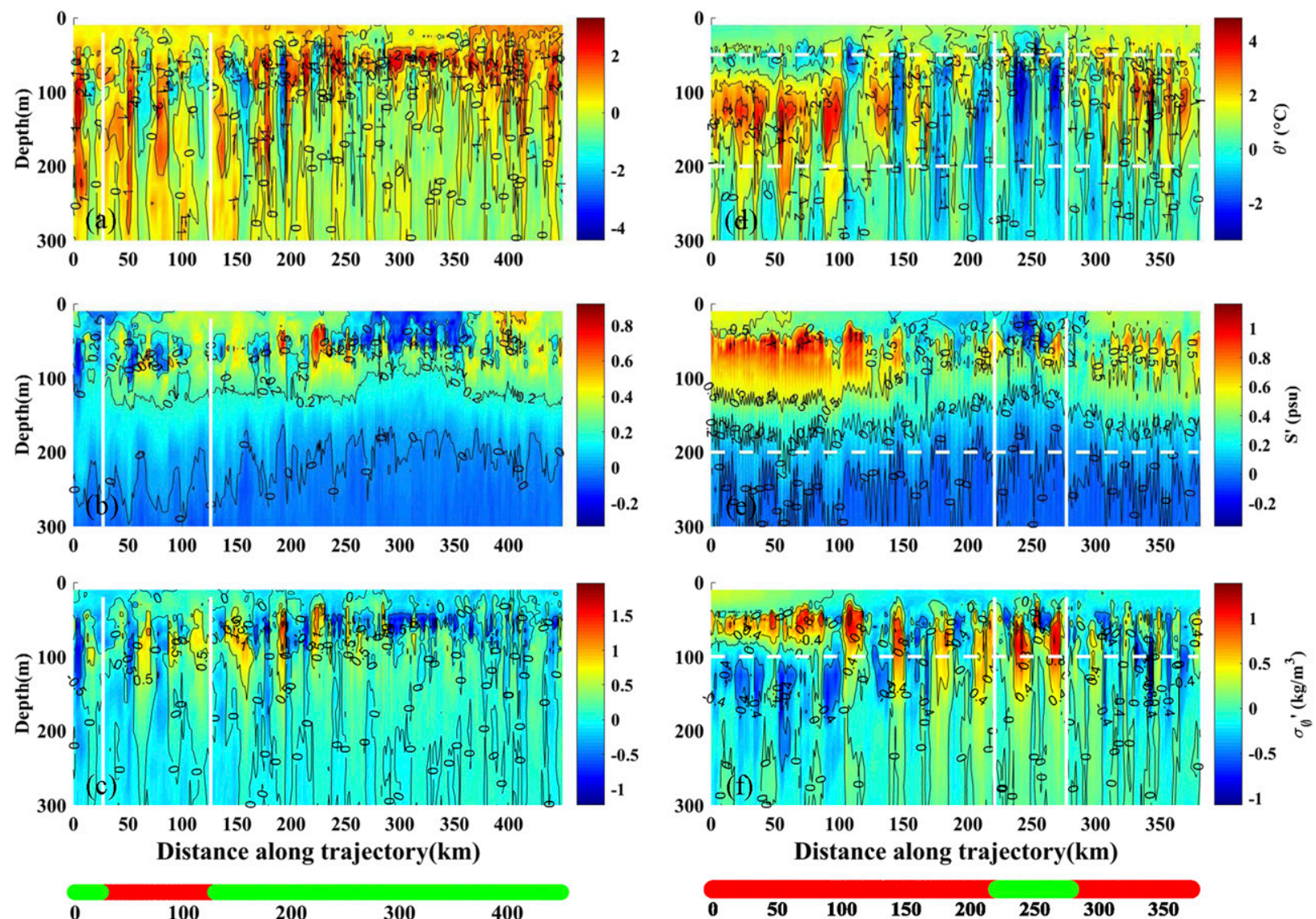

FIG. 16. Vertical sections of $\theta^{\prime}, S^{\prime}$ and $\sigma_{0}^{\prime}$ obtained by gliders (a),(b),(c) 5 and (d),(e),(f) 6 . The red dots denote the profiles inside the eddy, and the green ones are profiles outside the eddy. The horizontal dashed white lines in (d)-(f) are described in the text.

transects in the northwest part of the eddy during 517 August 2017. Throughout the mission, glider 8 sails inside the eddy all of the time. As shown in Figs. 14d and $14 \mathrm{f}$, the isotherm of $20^{\circ} \mathrm{C}$ and isopycnal of $25 \mathrm{~kg} \mathrm{~m}^{-3}$ are located at about 150 and $180 \mathrm{~m}$ depth, respectively, consistent with the corresponding depths obtained by gliders 5 and 6 . The salinity trapped within the eddy could reach up to more than 34.8 psu at about $120 \mathrm{~m}$. The maximum anomalies of $\theta$ and $S$ are about $3^{\circ} \mathrm{C}$ at $120 \mathrm{~m}$ and 0.8 psu at $50 \mathrm{~m}$, respectively (Figs. 17a,b). The maximum value of $\sigma_{0}^{\prime}$ is positive $0.6 \mathrm{~kg} \mathrm{~m}^{-3}$ at $50 \mathrm{~m}$ (Fig. $17 \mathrm{c}$ ). Glider 10 collects data from the southeast of the eddy between gliders 5 and 6 during 4-27 August 2017. As shown in Figs. 17d, 17e, and 17f, the maximum values of $\theta^{\prime}, S^{\prime}$, and $\sigma_{0}^{\prime}$ obtained by glider 10 are about $3^{\circ} \mathrm{C}, 0.4 \mathrm{psu}$, and $0.5 \mathrm{~kg} \mathrm{~m}^{-3}$. Similar to the distributions of $\sigma_{0}^{\prime}$ obtained by gliders 5 and 8 , negative values appear among positive values in the eddy. However, the values of $S^{\prime}$ and $\sigma_{0}^{\prime}$ in the northwest (glider 8 ) are slightly higher than those in the southeast (glider 10) of the eddy. Moreover, at the surface, it is clearly seen that the signal of $\theta^{\prime}$ appears on the eddy boundary whereas it is invisible inside the eddy core (shown in Figs. 16d and 17d). The depth of the maximum $\theta^{\prime}$ grows with the distance from the eddy center. On the contrary, $\sigma_{0}^{\prime}$ is not discernable on the eddy boundary, whereas it can be observed near the eddy center (Figs. $16 \mathrm{f}$ and 17f). Also the depth of maximum $\sigma_{0}^{\prime}$ deepens with the increasing distance from the eddy center.

\section{d. Chlorophyll, CDOM, and DO concentration sections}

Carrying the FLBBCDXMUN-3947 sensor, the glider 8 took transects within the northwestern anticyclonic eddy from 5 to 17 August 2017 to give us a fine characterization of the chlorophyll, CDOM, and DO concentration distribution inside the eddy. As shown in Fig. 18c, the values $>6 \mathrm{mg} \mathrm{L}^{-1}$ of the DO concentration appear above the isopycnal of $25.5 \mathrm{~kg} \mathrm{~m}^{-3}$, at about 200-m depth. The maximum value of about $7.5 \mathrm{mg} \mathrm{L}^{-1}$ is observed to exist between the isopycnals of 21.5 and $23 \mathrm{~kg} \mathrm{~m}^{-3}$ across the eddy, which are corresponding to about 50and $80-\mathrm{m}$ depths, respectively. Below depth where the higher values exist, the DO concentration decreases with the depth. Below 700-m depth, the concentration 

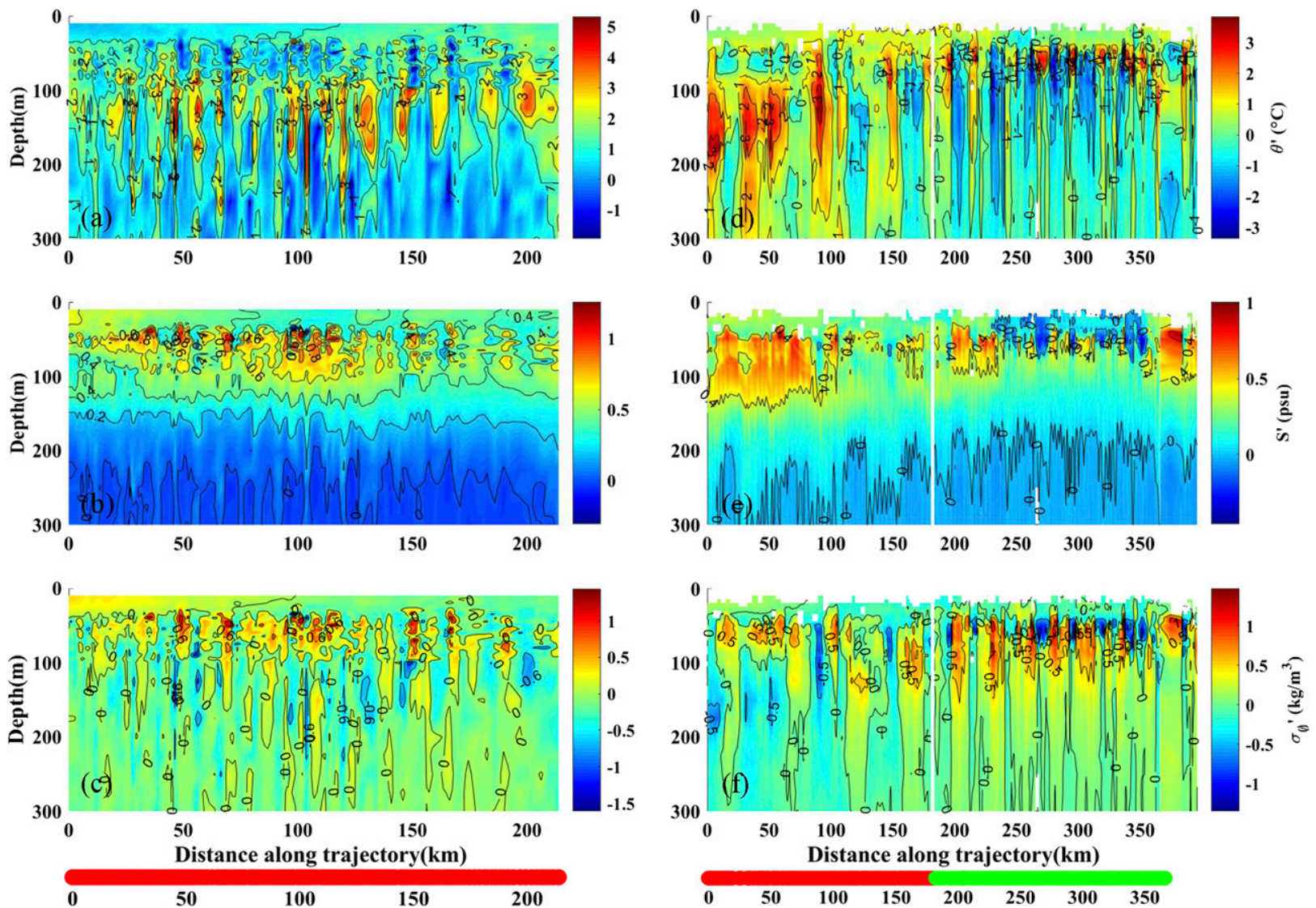

FIG. 17. As in Fig. 16, but for gliders (a),(b),(c) 8 and (d),(e),(f) 10.

decreases to less than $3 \mathrm{mg} \mathrm{L}^{-1}$. The distribution of chlorophyll concentration along the glider trajectory is presented in Figs. 18a and 18b. The higher values up to $1.2 \mu \mathrm{g} \mathrm{L}^{-1}$ lie between the isopycnals of 23 and $24 \mathrm{~kg} \mathrm{~m}^{-3}$, corresponding to about the depth of 80 and $120 \mathrm{~m}$, respectively, just below the depth of the higher DO concentration, while the lower values appear in shallower and deeper layers. Below the isopycnal of $25 \mathrm{~kg} \mathrm{~m}^{-3}$, namely about $180 \mathrm{~m}$, the concentration is reduced to less than $0.17 \mu \mathrm{g} \mathrm{L}^{-1}$. From Fig. 18d, it is clearly noted that the CDOM concentration increases with depth. At the sea surface, the concentration is relatively low, with a mean value of less than $1.23 \mathrm{ppb}$ above $50 \mathrm{~m}$, whereas the concentration reaches up to more than $2.4 \mathrm{ppb}$ in the deeper layers, with a mean value of more than $2.2 \mathrm{ppb}$ between 500 and $800 \mathrm{~m}$.

\section{e. Three-dimensional structure of the eddy}

To investigate the 3D structure of the anticyclonic eddy, the composite analysis was performed. The positions of glider profiles, which have been transferred to the eddy center-origin coordinate system, were plotted in Fig. 19. Figure 20 shows the $\theta^{\prime}$ field of the composite eddy at different depth levels. Above 50-m depth, the warm core is invisible. However, there is a discernable signal of the mesoscale anticyclonic eddy in the eddy boundary area, in agreement with the discussion in the vertical sections. At $100-\mathrm{m}$ depth, the isotherm of $\theta^{\prime}>$ $1.5^{\circ} \mathrm{C}$ encloses the eddy center. The maximum value at $100 \mathrm{~m}$ near eddy center is $>1.8^{\circ} \mathrm{C}$, higher than that of the ambient water. The maximum $\theta^{\prime}$ are $>1.1^{\circ} \mathrm{C}$ at $200 \mathrm{~m}$ and $>0.7^{\circ} \mathrm{C}$ at $300 \mathrm{~m}$, respectively. The mesoscale signals exhibit strongest intensity at the thermocline (more than $3^{\circ} \mathrm{C}$ at about $120-\mathrm{m}$ depth) and the magnitude decreases quickly with depth, agreeing well with the study of the literature (Shu et al. 2019). The eddy can penetrate more than $900 \mathrm{~m}$ (not shown here), with the maximum $\theta^{\prime}>$ $0.1^{\circ} \mathrm{C}$ at a depth of $900 \mathrm{~m}$. The horizontal distribution of the $\theta^{\prime}$ field presents an irregular structure. This may result from the complex interaction between currents and eddies (Qiu et al. 2018), which may modulate the structure of eddy. As shown in Fig. 201, the mean $\theta^{\prime}$ inside the composite eddy displays a reversed "C" shape in the upper layer and approaches zero in the deeper layer. The maximum value of the mean $\theta^{\prime}$ can reach $1.55^{\circ} \mathrm{C}$ at $120 \mathrm{~m}$, the thermocline layer. Moreover, the 

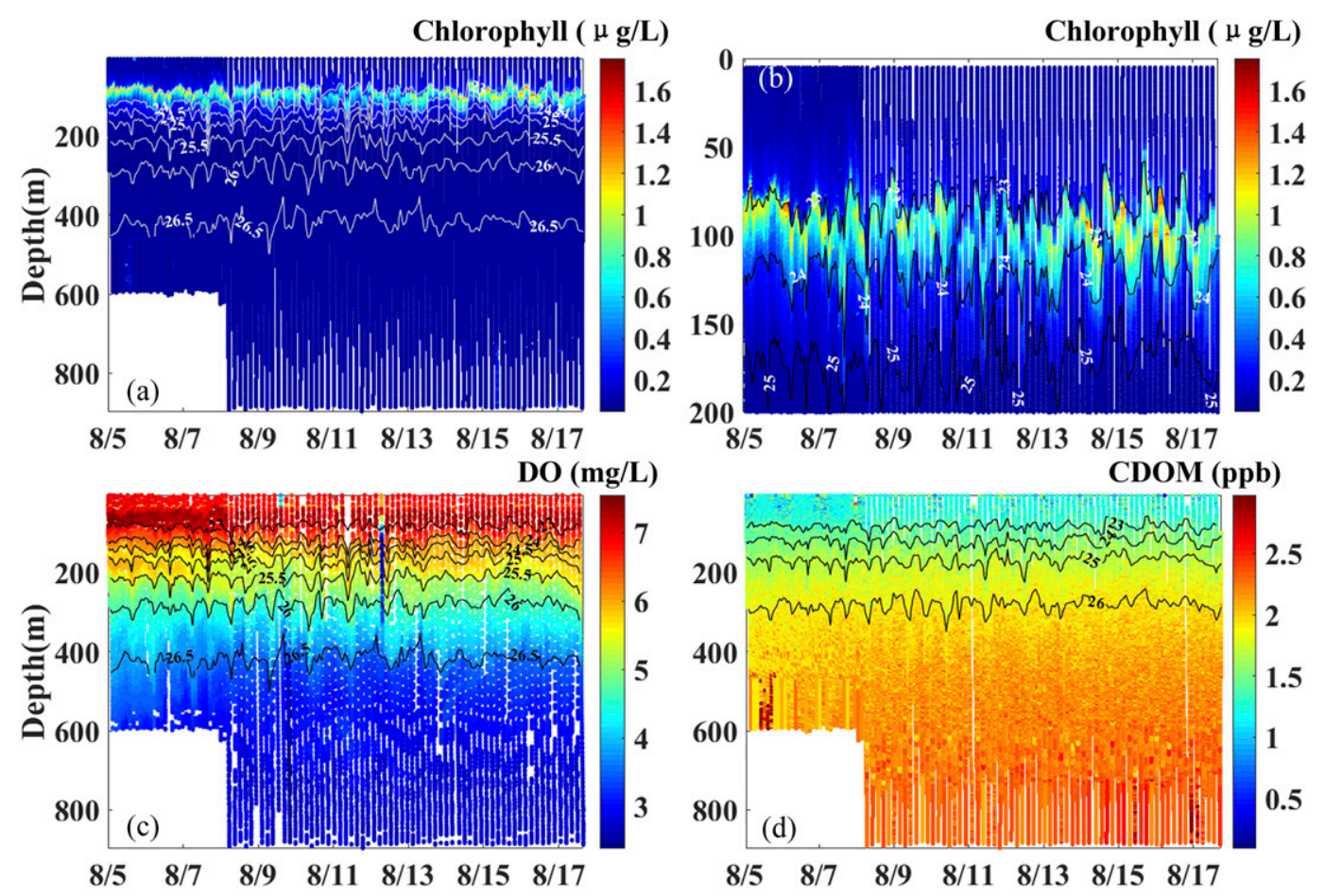

FIG. 18. Vertical sections of (a) chlorophyll concentration, (b) chlorophyll concentration above $200 \mathrm{~m}$, (c) DO concentration, and (d) CDOM concentration obtained by glider 8 .

mean $\theta^{\prime}$ keeps nonzero value at depths of more than $900 \mathrm{~m}$, the maximum depth that the 12 gliders have sampled in the experiment, indicating that the observed anticyclonic eddy penetrates more than $900 \mathrm{~m}$ in depth.

The horizontal distribution of the composite eddy salinity anomaly at different depths is plotted. As shown in Fig. 21, the distribution of $S^{\prime}$ has a great difference from that of $\theta^{\prime}$ illustrated in Fig. 20. First of all, the eddy is clearly discernable on the surface, different from the distribution of $\theta^{\prime}$. Above 50-m depth, the 0.5-psu isoline of $S^{\prime}$ surrounds the eddy core. The maximum value of $S^{\prime}$ in the eddy reaches up to about 0.8 psu at $50-\mathrm{m}$ depth. Then $S^{\prime}$ decreases with the depth, similar to the $\theta^{\prime}$ field, but falls down to 0.1 psu at $200-\mathrm{m}$ depth. Below $300 \mathrm{~m}$, the salinity remains almost identical to that of the surrounding water, with $S^{\prime}$ close to zero. In Fig. 211, the mean $S^{\prime}$ inside the composite eddy is plotted. Similar to that of the mean $\theta^{\prime}$, the curve of the mean $S^{\prime}$ also shows a reversed "C" shape in the upper layer. It can be seen that, the maximum value of the mean $S^{\prime}$ is about 0.5 psu at $50 \mathrm{~m}$ and reduces rapidly to zero at about $300 \mathrm{~m}$. Above $300 \mathrm{~m}$, the mean $S^{\prime}$ maintains positive values, representing the saltier water inside the eddy, and changes to be zero below $300 \mathrm{~m}$, indicating that the influence depth of the eddy on salinity distribution may be less than $300 \mathrm{~m}$.

To give a clear view of the 3D structure of the anticyclonic eddy, the 3D structures of $\theta^{\prime}$ above $900-$ and 350-m depth and $S^{\prime}$ above 900- and 300-m depth are illustrated, respectively, in Fig. 22. The black lines connect the black dots that mark the origin of the eddy center-origin coordinate system at each depth level. As shown in Fig. 22a, the influence of the eddy penetrates more than $900 \mathrm{~m}$. From the surface to $900-\mathrm{m}$ depth, the eddy center axis tilts much with depth. Below $150 \mathrm{~m}$, the eddy center is not clearly visible because the information about the eddy center is not collected by the gliders resulting from its tilting. However, part of the signals of the eddy is still discernable. As shown in Fig. 22b, the eddy center axis tilts little above $150 \mathrm{~m}$, while a larger
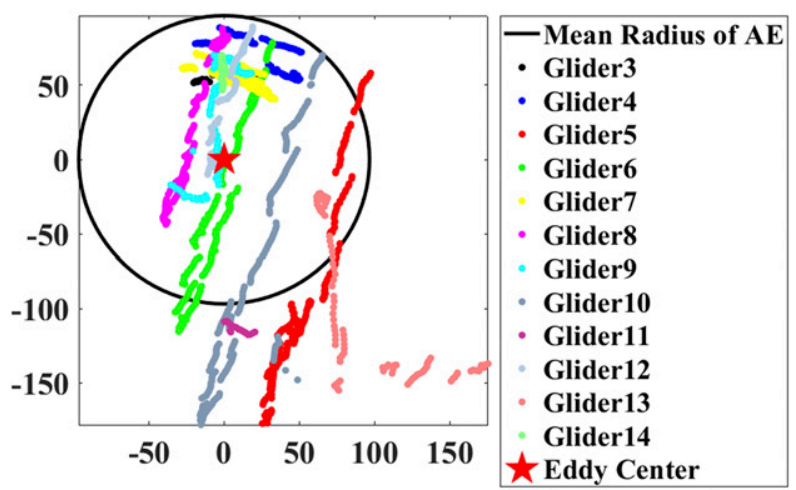

FIG. 19. Positions of glider profiles in the eddy centered-origin coordinate system. 

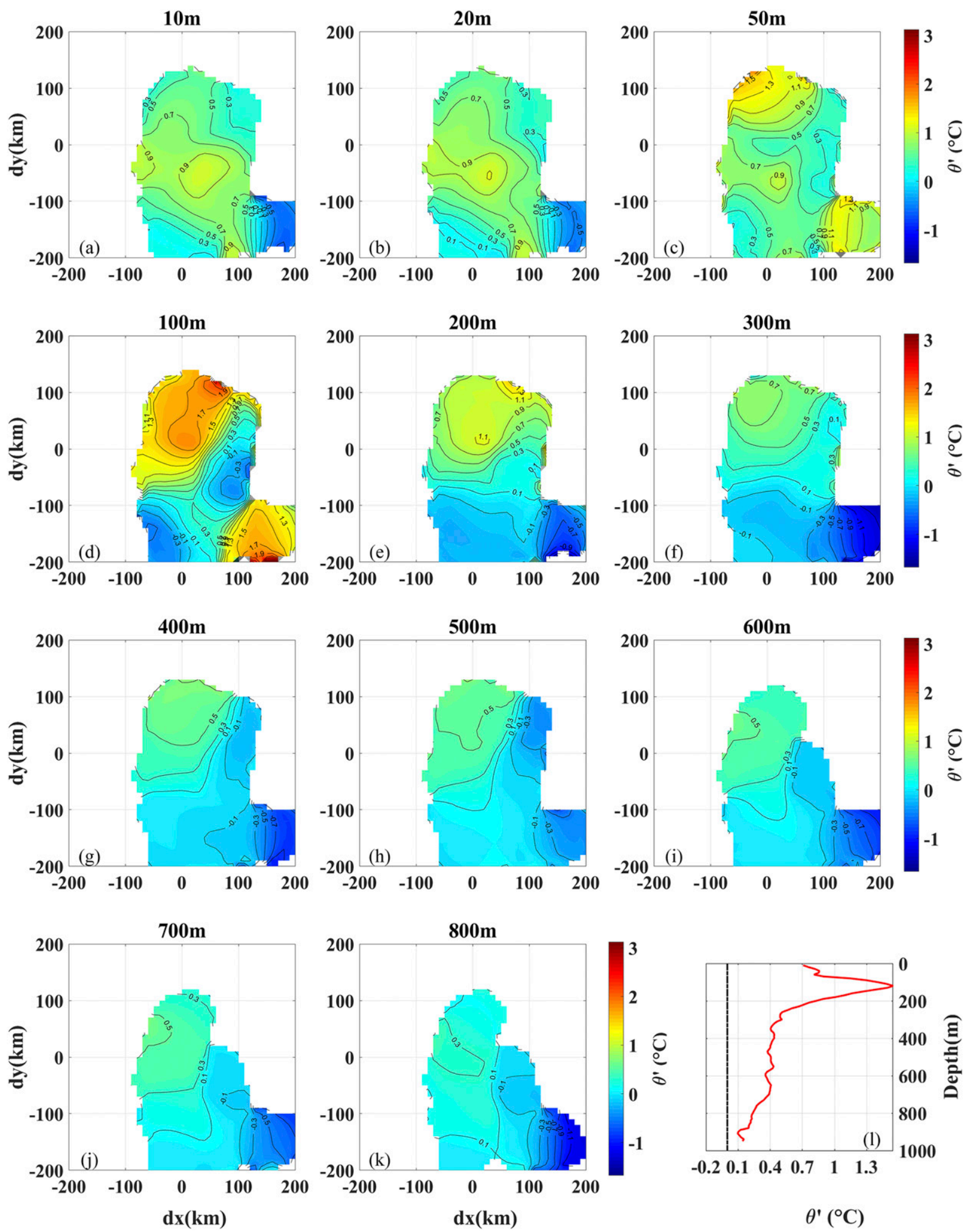

FIG. 20. The $\theta^{\prime}$ in the composite eddy: (a) 10, (b) 20, (c) 50, (d) 100, (e) 200, (f) 300, (g) 400, (h) 500, (i) 600, (j) 700, (k) and $800 \mathrm{~m}$ and (l) the mean value of $\theta^{\prime}$. The dashed black line and solid red line in (l) represent the reference value of zero and the mean $\theta^{\prime}$, respectively. 

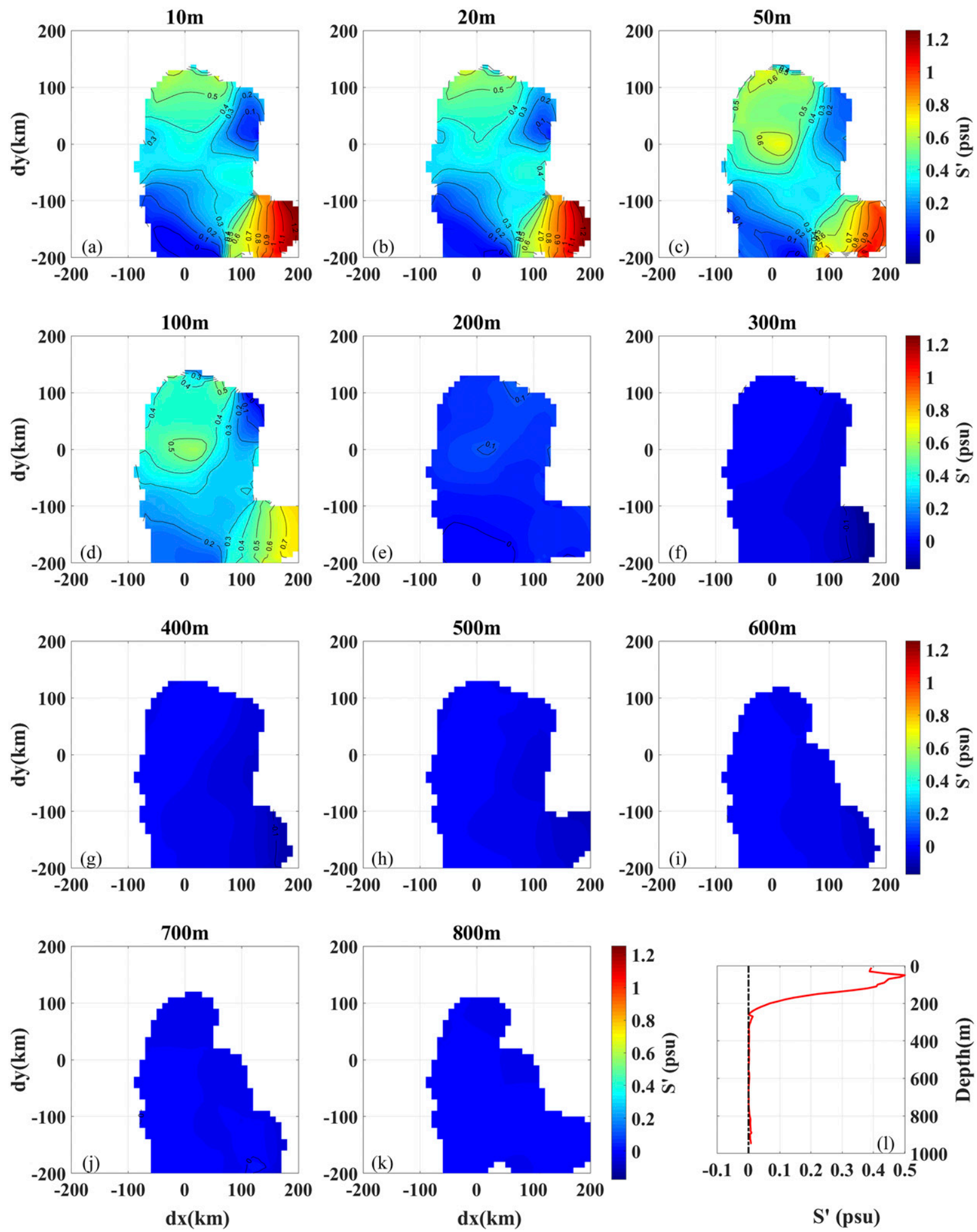

FIG. 21. As in Fig. 20, but for $S^{\prime}$. 

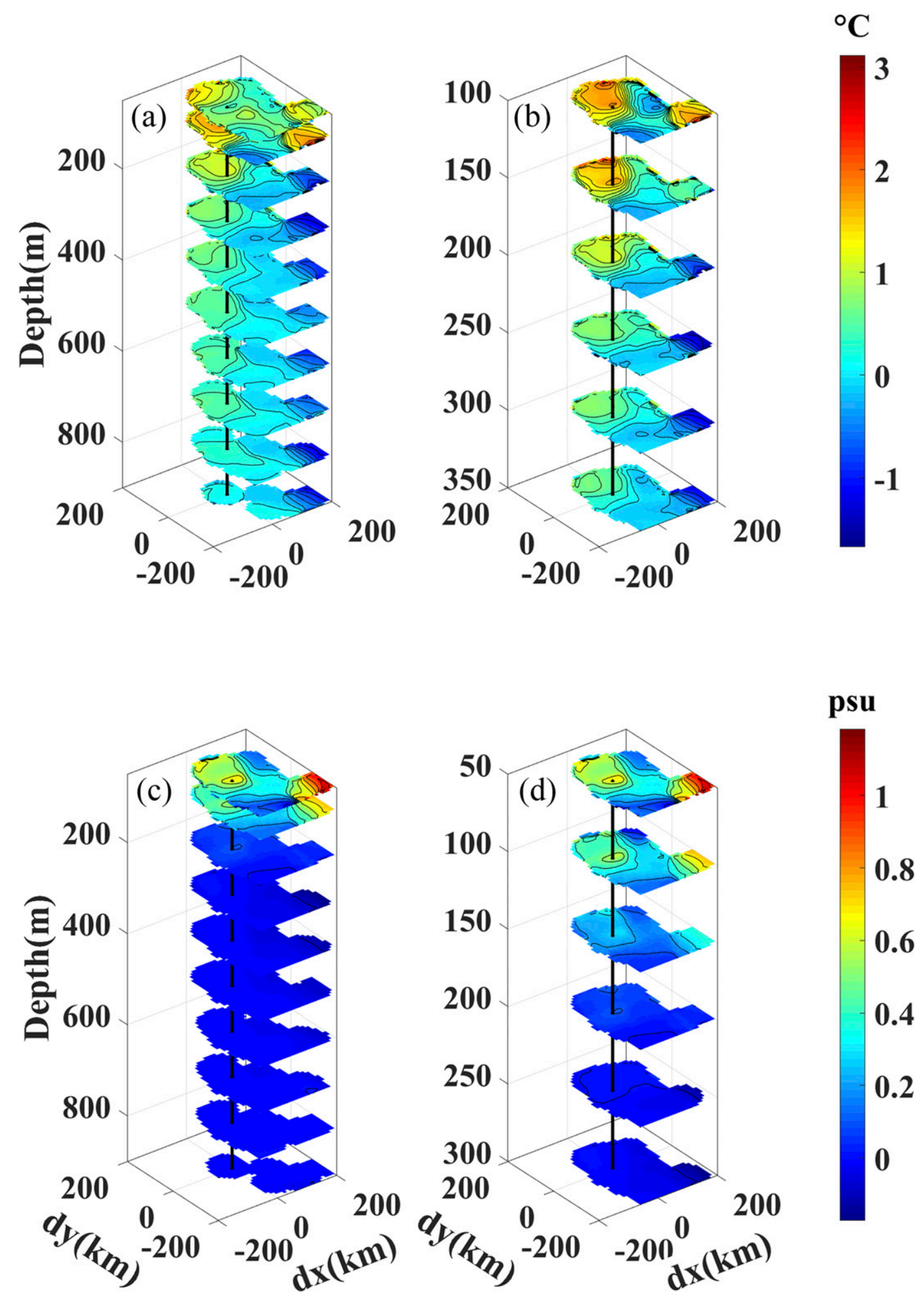

FIG. 22. Three-dimensional structures of (a) $\theta^{\prime}$ above $900 \mathrm{~m}$, (b) $\theta^{\prime}$ above $350 \mathrm{~m}$, (c) $S^{\prime}$ above $900 \mathrm{~m}$, and (d) $S^{\prime}$ above $300 \mathrm{~m}$. 
shift happens below $150 \mathrm{~m}$. In Figs. 22c and 22d, the tilting of the eddy center axis is not obvious because of the limited depth of the salinity anomaly inside the eddy.

\section{Discussion and conclusions}

By merging the dataset collected by 12 Petrel II gliders and the satellite data from CMEMS, we analyze the fine three-dimensional structure of an anticyclonic eddy in NSCS. Based on the satellite dataset, the track, center position, radius, amplitude, and translation speed of the eddy are estimated. The eddy, with the mean radius of $98 \mathrm{~km}$ and mean elevation of about $10.49 \mathrm{~cm}$ in the center at the sea surface, moves toward west with a translation speed of about $9.16 \mathrm{~cm} \mathrm{~s}^{-1}$. To investigate the origin of the eddy, the ADT time evolution of the studied domain is illustrated to express the Kuroshio eddy shedding. Moreover, the $T-S$ diagram of water mass inside the eddy, the NSCS and Kuroshio are plotted. The $T-S$ property of the water mass inside eddy is more similar to that of the Kuroshio water above $300 \mathrm{~m}$, indicating that the eddy may generate in the Kuroshio. Near the eddy center, the isotherm of $20^{\circ} \mathrm{C}$ and isopycnal of $25 \mathrm{~kg} \mathrm{~m}^{-3}$ both sink $30 \mathrm{~m}$, with the former sinking from about 120 to about $150 \mathrm{~m}$ and the latter deepening from about 150 to $180 \mathrm{~m}$. Most of $\theta^{\prime}$ values inside the eddy are between 50 and $200 \mathrm{~m}$. The maximum depth of $S^{\prime}$ is about $200 \mathrm{~m}$. The negative $\sigma_{0}^{\prime}$ exists mostly below $100 \mathrm{~m}$ while the positive anomaly is located in the mixed layer. The distributions of $\theta^{\prime}, S^{\prime}$, and $\sigma_{0}^{\prime}$ in the northwest and southeast of the eddy have great similarity. However, the $S^{\prime}$ and $\sigma_{0}^{\prime}$ in the northwest are slightly higher than those in the southeast of the eddy. The eddy can penetrate to more than 900-m depth. In the structure of the composite anticyclonic eddy, the maximum value of $\theta^{\prime}\left(>3^{\circ} \mathrm{C}\right.$ ) and $S^{\prime}$ (about $0.8 \mathrm{psu}$ ) are observed near eddy center at about 120- and 50-m depth, respectively. The signals for $\theta^{\prime}$ appear to be strongest at the thermocline, whereas the strongest intensity of $S^{\prime}$ is located at about $50 \mathrm{~m}$. Furthermore, $\theta^{\prime}$ and $S^{\prime}$ decreases quickly with depth. Both mean $\theta^{\prime}$ and $S^{\prime}$ inside the eddy show a reversed " $C$ " shape in the upper layer and close to zero in the deeper. The eddy center axis tilts with depth. Above $150 \mathrm{~m}$, the eddy center axis tilts little while the tilt becomes larger below $150 \mathrm{~m}$. The maximum DO concentration of about $7.5 \mathrm{mg} \mathrm{L}^{-1}$ appears between the isopycnals of 21.5 and $23 \mathrm{~kg} \mathrm{~m}^{-3}$ across the eddy, corresponding to the depth of 50 and $80 \mathrm{~m}$, respectively, while the lower values appear in shallower and deeper layers. The higher values of the chlorophyll concentration exist between 80 and $120 \mathrm{~m}$, just below that of the dissolved oxygen concentration, with the maximum value of more than $1.2 \mu \mathrm{g} \mathrm{L}^{-1}$. Similar to the distribution of DO concentration, below depth where the higher values exist, the chlorophyll concentration decreases with depth. The CDOM concentration increases with the depth from the surface to the glider diving depth, with the mean values of less than $1.23 \mathrm{ppb}$ above $50 \mathrm{~m}$ and more than $2.2 \mathrm{ppb}$ between 500 and $800 \mathrm{~m}$.

The dataset collected during the experiment by multiple underwater gliders contributes to the research on the fine 3D structure of the mesoscale eddy in the northern South China Sea, which demonstrates that multiple underwater gliders have the ability to resolve the fine structure of the mesoscale eddies. The results may be improved in the future by piloting the gliders with adjustable waypoints to cross the eddy center and along the eddy borders to give a more detailed description of the eddy structure.

Acknowledgments. We acknowledge the support of the National Key R\&D Program of China (Grants 2016YFC0301100 and 2017YFC0305902), the Research Funds from Shenzhen Investment Holdings Company Limited, National Natural Science Foundation of China (Grants 51721003, 51722508, and 11902219), Natural Science Foundation of Tianjin City (Grants 18JCQNJC05100 and 18JCJQJC46400), Wenhai Program, Director Foundation, Aoshan Talent Cultivation Program (Grants 2017ASTCP-OS05 and 2017ASTCP-OE01) of QNLM, the Marine S\&T Fund of Shandong Province for Pilot National Laboratory for Marine Science and Technology (Qingdao) (Grant 2018SDKJ0205), the joint project of Qingdao marine engineering equipment and technology of think-tank, and China Scholarship Council (Grant 201706250178). In addition, this study benefited from the SLA/ADT data generated by DUACS and distributed by CMEMS and the monthly average climatological temperature and salinity distributed by WOA13.

\section{REFERENCES}

Amores, A., O. Melnichenko, and N. Maximenko, 2017: Coherent mesoscale eddies in the North Atlantic subtropical gyre: 3-D structure and transport with application to the salinity maximum. J. Geophys. Res. Oceans, 122, 23-41, https://doi.org/ 10.1002/2016JC012256.

Baird, M. E., and Coauthors, 2011: The effect of surface flooding on the physical-biogeochemical dynamics of a warm-core eddy off southeast Australia. Deep-Sea Res. II, 58, 592-605, https:// doi.org/10.1016/j.dsr2.2010.10.002.

Bouffard, J., A. Pascual, S. Ruiz, Y. Faugère, and J. Tintoré, 2010: Coastal and mesoscale dynamics characterization using altimetry and gliders: A case study in the Balearic Sea. J. Geophys. Res., 115, C10029, https://doi.org/10.1029/2009JC006087.

Boyer, T. P., and Coauthors, 2013: World Ocean Database 2013. NOAA Atlas NESDIS 72, 208 pp., https://data.nodc.noaa.gov/ woa/WOD13/DOC/wod13_intro.pdf.

Chaigneau, A., M. L. Texier, G. Eldin, C. Grados, and O. Pizarro, 2011: Vertical structure of mesoscale eddies in the eastern 
South Pacific Ocean: A composite analysis from altimetry and Argo profiling floats. J. Geophys. Res., 116, C11025, https:// doi.org/10.1029/2011JC007134.

Chen, X., D. Hu, K.-f. Mao, and Y. Li, 2018: Detailed investigation of the three-dimensional structure of a mesoscale cold eddy in the Kuroshio extension region. J. Oper. Oceanogr., 11, 87-99, https://doi.org/10.1080/1755876X.2018.1505069.

Chu, X., H. Xue, Y. Qi, G. Chen, Q. Mao, D. Wang, and F. Chai, 2014: An exceptional anticyclonic eddy in the South China Sea in 2010. J. Geophys. Res. Oceans, 119, 881-897, https://doi.org/ 10.1002/2013JC009314.

Cotroneo, Y., G. Aulicino, S. Ruiz, A. Pascual, G. Budillon, G. Fusco, and J. Tintoré, 2016: Glider and satellite high resolution monitoring of a mesoscale eddy in the Algerian basin: Effects on the mixed layer depth and biochemistry. J. Mar. Syst., 162, 73-88, https://doi.org/10.1016/j.jmarsys.2015.12.004.

Davies, A. R., F. Veron, and M. J. Oliver, 2019: Biofloat observations of a phytoplankton bloom and carbon export in the Drake Passage. Deep-Sea Res. I, 146, 91-102, https://doi.org/ 10.1016/J.DSR.2019.02.004.

Dickey, T., E. C. Itsweire, M. Moline, and M. Perry, 2008: Introduction to the Limnology and Oceanography special issue on autonomous and Lagrangian platforms and sensors (ALPS). Limnol. Oceanogr., 53, 2057-2061, https://doi.org/ 10.4319/1o.2008.53.5_part_2.2057.

Dong, D., P. Brandt, P. Chang, F. Schütte, X. Yang, J. Yan, and J. Zeng, 2017: Mesoscale eddies in the northwestern Pacific Ocean: Three-dimensional eddy structures and heat/salt transports. J. Geophys. Res. Oceans, 122, 9795-9813, https://doi.org/ 10.1002/2017JC013303.

Eriksen, C. C., T. J. Osse, R. D. Light, T. Wen, T. W. Lehman, P. L. Sabin, J. W. Ballard, and A. M. Chiodi, 2001: Seaglider: A long-range autonomous underwater vehicle for oceanographic research. IEEE J. Oceanic Eng., 26, 424-436, https:// doi.org/10.1109/48.972073.

Faghmous, J. H., I. Frenger, Y. Yao, R. Warmka, A. Lindell, and V. Kumar, 2015: A daily global mesoscale ocean eddy dataset from satellite altimetry. Sci. Data, 2, 150028, https://doi.org/ 10.1038/SDATA.2015.28

He, Q., H. Zhan, S. Cai, Y. He, G. Huang, and W. Zhan, 2018: A new assessment of mesoscale eddies in the South China Sea: Surface features, three-dimensional structures, and thermohaline transports. J. Geophys. Res. Oceans, 123, 4906-4929, https://doi.org/10.1029/2018JC014054.

Hodges, B. A., and D. M. Fratantoni, 2009: A thin layer of phytoplankton observed in the Philippine Sea with a synthetic moored array of autonomous gliders. J. Geophys. Res., 114, C10020, https://doi.org/10.1029/2009JC005317.

Hu, J., J. Gan, Z. Sun, J. Zhu, and M. Dai, 2011: Observed threedimensional structure of a cold eddy in the southwestern South China Sea. J. Geophys. Res., 116, C05016, https://doi.org/ 10.1029/2010JC006810.

Jia, Y., and Q. Liu, 2004: Eddy shedding from the Kuroshio bend at Luzon Strait. J. Oceanogr., 60, 1063-1069, https://doi.org/ 10.1007/s10872-005-0014-6.

Li, Q., 2007: Nutrient biogeochemistry of mesoscale eddies in the Sargasso Sea. Ph.D. dissertation, University of Miami, 186 pp.

Lin, X., C. Dong, D. Chen, Y. Liu, J. Yang, B. Zou, and Y. Guan, 2015: Three-dimensional properties of mesoscale eddies in the South China Sea based on eddy-resolving model output. DeepSea Res. I, 99, 46-64, https://doi.org/10.1016/j.dsr.2015.01.007.

Liu, F., Y.-h. Wang, Z.-l. Wu, and S.-x. Wang, 2017: Motion analysis and trials of the deep sea hybrid underwater glider
Petrel-II. China Ocean Eng., 31, 55-62, https://doi.org/ 10.1007/s13344-017-0007-4.

Liu, Z., X. Chen, J. Yu, D. Xu, and C. Sun, 2019: Kuroshio intrusion into the South China Sea with an anticyclonic eddy: Evidence from underwater glider observation. J. Oceanol. Limnol., 37, 1469-1480, https://doi.org/10.1007/S00343-019-8290-y.

Mann, K. H., and J. R. Lazier, 2013: Dynamics of Marine Ecosystems: Biological-Physical Interactions in the Oceans. John Wiley and Sons, $512 \mathrm{pp}$.

Martin, J., C. Lee, C. Eriksen, C. Ladd, and N. Kachel, 2009: Glider observations of kinematics in a Gulf of Alaska eddy. J. Geophys. Res., 114, C12021, https://doi.org/10.1029/2008JC005231.

Nardelli, B. B., 2013: Vortex waves and vertical motion in a mesoscale cyclonic eddy. J. Geophys. Res. Oceans, 118, 56095624, https://doi.org/10.1002/jgrc.20345.

Nencioli, F., V. S. Kuwahara, T. D. Dickey, Y. M. Rii, and R. R. Bidigare, 2008: Physical dynamics and biological implications of a mesoscale eddy in the lee of Hawaii: Cyclone opal observations during E-Flux III. Deep-Sea Res. II, 55, 1252-1274, https://doi.org/10.1016/j.dsr2.2008.02.003.

Petillo, S., H. Schmidt, and A. Balasuriya, 2011: Constructing a distributed AUV network for underwater plume-tracking operations. Int. J. Distrib. Sens. Networks, 8, 191235, https:// doi.org/10.1155/2012/191235.

Qiu, C., H. Mao, Y. Wang, J. Yu, D. Su, and S. Lian, 2018: An irregularly shaped warm eddy observed by Chinese underwater gliders. J. Oceanogr., 75, 139-148, https://doi.org/10.1007/ S10872-018-0490-0.

Richardson, P. L., 1983: Eddy kinetic energy in the North Atlantic from surface drifters. J. Geophys. Res., 88, 4355-4367, https:// doi.org/10.1029/JC088iC07p04355.

Sherman, J., R. E. Davis, W. Owens, and J. Valdes, 2001: The autonomous underwater glider "Spray." IEEE J. Oceanic Eng., 26, 437-446, https://doi.org/10.1109/48.972076.

Shu, Y., P. Xiu, H. Xue, J. Yao, and J. Yu, 2016: Glider-observed anticyclonic eddy in northern South China Sea. Aquat. Ecosyst. Health Manage., 19, 233-241, https://doi.org/10.1080/ 14634988.2016.1208028.

_ J. J. Chen, S. Li, Q. Wang, J. Yu, and D. Wang, 2019: Fieldobservation for an anticyclonic mesoscale eddy consisted of twelve gliders and sixty-two expendable probes in the northern South China Sea during summer 2017. Sci. China Earth Sci., 62, 451-458, https://doi.org/10.1007/s11430-018-9239-0.

Stammer, D., 1997: Global characteristics of ocean variability estimated from regional TOPEX/Poseidon altimeter measurements. J. Phys. Oceanogr., 27, 1743-1769, https://doi.org/ 10.1175/1520-0485(1997)027<1743:GCOOVE > 2.0.CO;2.

Thomsen, S., T. Kanzow, G. Krahmann, R. J. Greatbatch, M. Dengler, and G. Lavik, 2016: The formation of a subsurface anticyclonic eddy in the Peru-Chile undercurrent and its impact on the near-coastal salinity, oxygen, and nutrient distributions. J. Geophys. Res. Oceans, 121, 476-501, https://doi.org/ 10.1002/2015JC010878.

Yang, G., F. Wang, Y. Li, and P. Lin, 2013: Mesoscale eddies in the northwestern subtropical Pacific Ocean: Statistical characteristics and three-dimensional structures. J. Geophys. Res. Oceans, 118, 1906-1925, https://doi.org/10.1002/jgrc.20164.

Yuan, D., W. Han, and D. Hu, 2006: Surface Kuroshio path in the Luzon Strait area derived from satellite remote sensing data.J. Geophys. Res., 111, C11007, https://doi.org/10.1029/ 2005JC003412.

Zhang, W.-Z., Q. Ni, and H. Xue, 2018: Composite eddy structures on both sides of the Luzon Strait and influence 
factors. Ocean Dyn., 68, 1527-1541, https://doi.org/10.1007/ s10236-018-1207-z.

Zhang, Z., Y. Zhang, W. Wang, and R. X. Huang, 2013a: Universal structure of mesoscale eddies in the ocean. Geophys. Res. Lett., 40, 3677-3681, https://doi.org/10.1002/grl.50736.

, W. Zhao, J. Tian, and X. Liang, 2013b: A mesoscale eddy pair southwest of Taiwan and its influence on deep circulation. J. Geophys. Res. Oceans, 118, 6479-6494, https://doi.org/ 10.1002/2013JC008994.

, J. Tian, B. Qiu, W. Zhao, P. Chang, D. Wu, and X. Wan, 2016: Observed 3D structure, generation, and dissipation of oceanic mesoscale eddies in the South China Sea. Sci. Rep., 6, 24349, https://doi.org/10.1038/srep24349.
-_, W. Zhao, B. Qiu, and J. Tian, 2017: Anticyclonic eddy sheddings from Kuroshio loop and the accompanying cyclonic eddy in the northeastern South China Sea. J. Phys. Oceanogr., 47, 1243-1259, https://doi.org/10.1175/JPO-D16-0185.1.

Zhao, J., A. Bower, J. Yang, and X. Lin, 2018: Meridional heat transport variability induced by mesoscale processes in the subpolar North Atlantic. Nat. Commun., 9, 1124, https:// doi.org/10.1038/s41467-018-03134-x.

Zhong, Y., A. Bracco, J. Tian, J. Dong, W. Zhao, and Z. Zhang, 2017: Observed and simulated submesoscale vertical pump of an anticyclonic eddy in the South China Sea. Sci. Rep., 7, 44011, https://doi.org/10.1038/srep44011. 